\title{
Equatorial GPS ionospheric scintillations over Kototabang, Indonesia and their relation to atmospheric waves from below
}

\author{
Tadahiko Ogawa $^{1 *}$, Yasunobu Miyoshi ${ }^{2}$, Yuichi Otsuka ${ }^{1}$, Takuji Nakamura ${ }^{3}$, and Kazuo Shiokawa ${ }^{1}$ \\ ${ }^{1}$ Solar-Terrestrial Environment Laboratory, Nagoya University, Toyokawa, Aichi 442-8507, Japan \\ ${ }^{2}$ Department of Earth and Planetary Sciences, Kyushu University, Fukuoka 812-8581, Japan \\ ${ }^{3}$ Research Institute for Sustainable Humanosphere, Kyoto University, Uji, Kyoto 611-0011, Japan
}

(Received October 5, 2007; Revised January 25, 2008; Accepted March 12, 2008; Online published May 14, 2009)

\begin{abstract}
Using Global Positioning System (GPS) satellites, we have been conducting equatorial ionospheric scintillation observations at Kototabang, Indonesia since January 2003. Scintillations caused by equatorial plasma bubbles appear between 2000 and 0100 LT in equinoctial months with a seasonal asymmetry, and their activity decreases with decreasing solar activity. A comparison between scintillation index $\left(S_{4}\right)$ and Earth's brightness temperature $\left(T_{\mathrm{bb}}\right)$ variations suggests that the scintillation activity can be related to tropospheric disturbances over the Indian Ocean to the west of Kototabang. To understand better the reasons of day-to-day variability of $S_{4}$, we analyze $S_{4}$, $T_{\mathrm{bb}}$ and lower thermospheric neutral wind $\left(\overline{u^{\prime 2}}\right)$ data. The results show that $S_{4}$ fluctuates with periods of about $2.5,5,8,14$ and 25 days, possibly due to atmospheric waves from below and that similar periods are also found in the $T_{\mathrm{bb}}$ and $\overline{u^{\prime 2}}$ variations. Using a general circulation model, we made numerical simulations to determine the behavior of neutral wind in the equatorial thermosphere. The results indicate the following: (1) 2- to 20-day waves dissipate rapidly above about an altitude of $125 \mathrm{~km}$, and 0.5 - to 3-hour waves become predominant above $100 \mathrm{~km}$, (2) zonal winds above $200 \mathrm{~km}$ altitude are, on the whole, eastward during sunset-sunrise, (3) zonal wind patterns due to short-period (1-4 h) atmospheric gravity waves (AGWs) above $120 \mathrm{~km}$ altitude change day by day, exhibit wavy structures with scale lengths of about $30-1000 \mathrm{~km}$ and, as a whole, move eastward at about $100^{-1}$ while changing patterns over time. These simulations suggest that the Rayleigh-Taylor instability responsible for plasma bubble generation can be seeded by AGWs with short periods of about $0.5-3 \mathrm{~h}$, and that background conditions necessary for this instability are modulated by planetary-scale atmospheric waves propagating up to an altitude of about $120 \mathrm{~km}$ from below.
\end{abstract}

Key words: Equatorial ionosphere, GPS scintillation, plasma bubble, atmospheric wave, tropospheric disturbance.

\section{Introduction}

One of the plasma disturbances peculiar to the nighttime equatorial ionosphere concerns the plasma bubbles that are generated in the bottomside of the $F$ region near sunset through the Rayleigh-Taylor (RT) plasma instability mechanism. Bubbles are recognized as spread echoes on ionograms (equatorial spread- $F$ ), and are accompanied by HFVHF radar echoes and ionospheric scintillations of satellite signals. Giant geomagnetic-conjugate bubbles extending up to $1800 \mathrm{~km}$ altitude over the geomagnetic equator have often been detected simultaneously with all-sky imagers at midlatitude in Japan and Australia (Otsuka et al., 2002; Shiokawa et al., 2004; Ogawa et al., 2005). Although bubble characteristics and fundamental physical processes generating bubbles have been well studied, many questions still remain to be answered for a full understanding of the electrodynamics related to bubbles and spread- $F$ (e.g., Abdu,

*Now at National Institute of Information and Communications Technology, Koganei, Tokyo 184-8795, Japan.

Copyright (c) The Society of Geomagnetism and Earth, Planetary and Space Sciences (SGEPSS); The Seismological Society of Japan; The Volcanological Society of Japan; The Geodetic Society of Japan; The Japanese Society for Planetary Sciences; TERRAPUB
2001). The issues that we are concerned with in this paper are the day-to-day variability of bubble occurrences and seeding processes of plasma perturbations that ultimately develop into bubbles through the RT instability.

Plasma bubbles are usually accompanied by field-aligned irregularities (FAIs) with various spatial scales. FAIs on the scale of a few meters cause coherent VHF radar backscatter (e.g., Woodman and LaHoz, 1976; Fukao et al., 2004), and those on a scale of a few hundred meter induce ionospheric scintillations when a Global Positioning System (GPS) radio wave penetrates into the horizontally moving FAI region (Beach and Kintner, 1999). Basu et al. (1983) observed $257-\mathrm{MHz}$ and $1.54-\mathrm{GHz}$ scintillations associated with plasma depletions that were detected with an in situ probe. Using the 47-MHz EAR radar and a 630-nm all-sky imager at Kototabang, Otsuka et al. (2004) found that 3.2$\mathrm{m}$ scale FAIs were confined within plasma bubbles. These observations indicate a GPS scintillation technique to be very useful to monitor continuously plasma bubble occurrences throughout day, season and year. GPS scintillations are caused by FAIs with a spatial scale of about $350 \mathrm{~m}$ (first Fresnel size) within and around bubbles.

Atmospheric gravity waves (AGWs) propagating in the equatorial thermosphere can seed plasma bubbles (e.g. Lin 


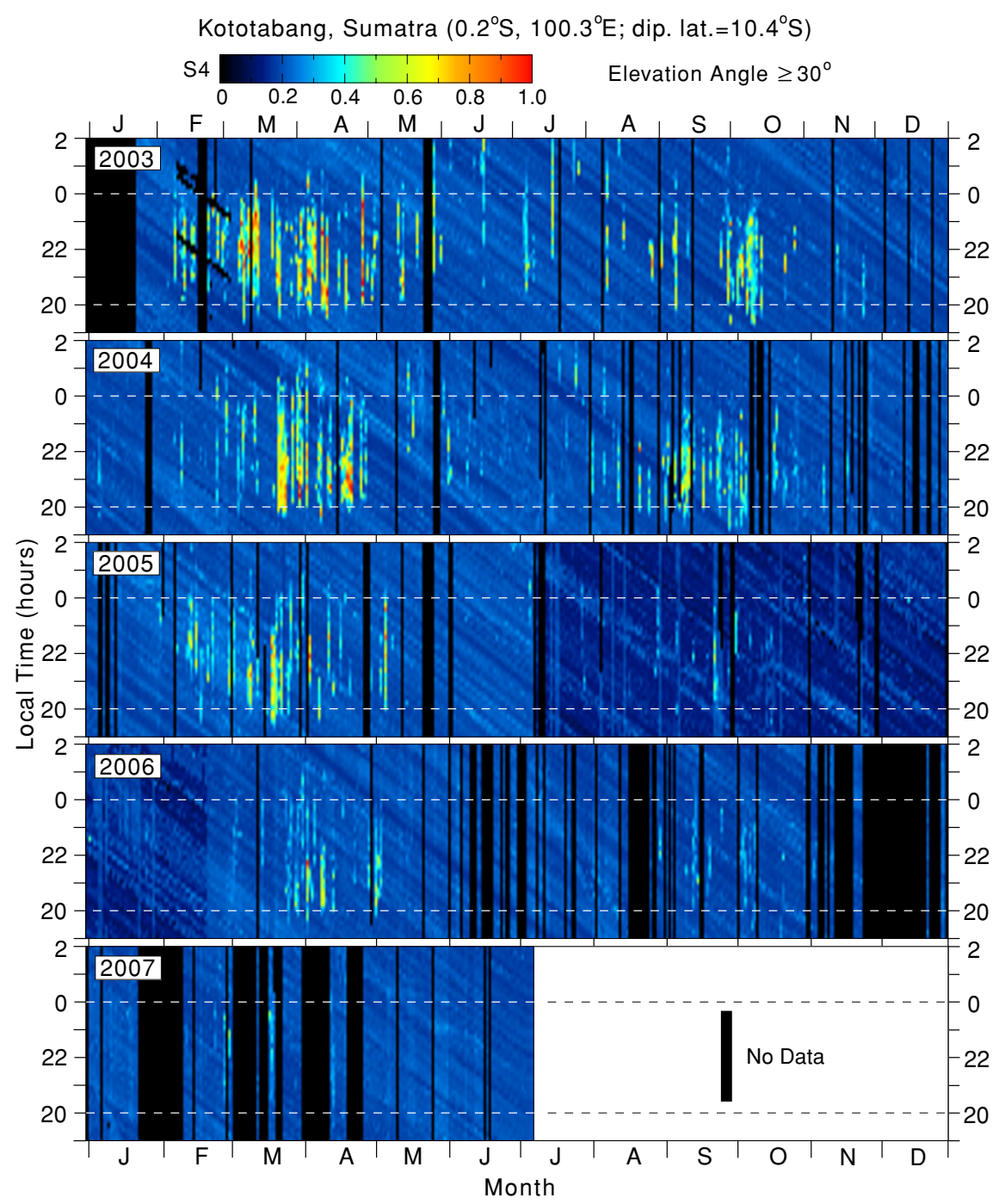

Fig. 1. Day-local time variations in the GPS scintillation index $S_{4}$ at Kototabang during January 2003-June 2007. $S_{4}$ values less than about 0.2 are due to background noise. Black portions represent no data due to instrumental problems.

et al., 2005) and cause a sinusoidal oscillation of the altitude of the bottomside $F$ layer (Kelley et al., 1981) and wavy ion density structures with east-west wavelengths of $150-800 \mathrm{~km}$ in the bottomside $F$ layer (Singh et al., 1997). Tsunoda (2005) stressed that development of a large-scale $(\sim 400 \mathrm{~km})$ wavy structure was necessary for spread- $F$ occurrence and to explain day-to-day variability of spread- $F$. Ogawa et al. (2005) found wavy plasma structures with scales of a few hundred to $1000 \mathrm{~km}$ within the northern and southern equatorial anomaly crests. Planetary waves (PWs) with periods longer than 2 days are known to modulate the equatorial mesosphere and ionosphere (Takahashi et al., 2005) and occurrences of the evening prereversal enhancement of the equatorial electric field and spread- $F$ (Abdu et al., 2006a). Thus, the role of AGWs and PWs, probably propagating from below, cannot be disregarded when trying to understand the seeding and modulation processes of plasma bubbles and also vertical coupling in the atmosphere-ionosphere system (Laštovička, 2006).

We have been monitoring GPS ionospheric scintillations at Kototabang, West Sumatra in Indonesia $\left(0.20^{\circ} \mathrm{S}\right.$, $100.32^{\circ} \mathrm{E}$; geomagnetic latitude $\simeq$ dip latitude $10.36^{\circ} \mathrm{S}$ ) near the geographic equator since January 2003. Using the data from 2003 and 2004, Ogawa et al. (2006) presented characteristics of equatorial ionospheric scintillations over Kototabang. They also compared scintillation activity with the Earth's black body temperature (a measure of tropospheric disturbance) in order to investigate possible dynamical coupling between the ionosphere/thermosphere and troposphere over the equator. The results suggested that some correlations can exist between the scintillation (bubble) occurrence and tropospheric disturbance over the Indian Ocean.

In this paper we show the scintillation characteristics during January 2003-June 2007 (during the declining phase of 11-year solar cycle) and make a wavelet analysis of scintillation, mesospheric/lower thermospheric wind and black body temperature data to investigate modulations of these parameters due to long-period ( $\geq 2$ days) atmospheric waves. Further, to know how PWs and AGWs behave in the equatorial mesosphere and thermosphere/ionosphere, we make numerical simulations of neutral winds at altitudes between the ground and about $500 \mathrm{~km}$, using a general circulation model with high spatial resolution. 


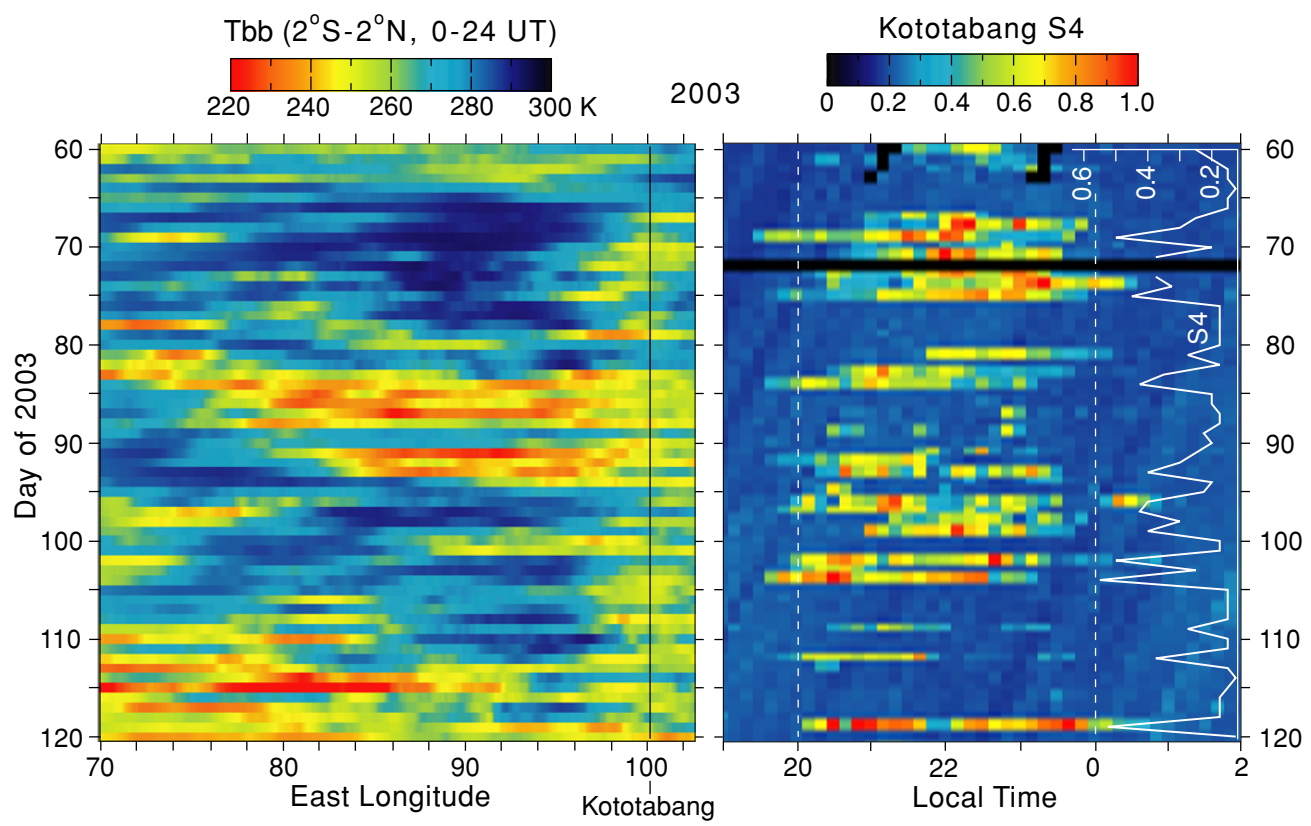

Fig. 2. Daily variations of black body temperature $T_{\mathrm{bb}}$, averaged over $2^{\circ} \mathrm{S}-2^{\circ} \mathrm{N}$ and $0000-2400 \mathrm{UT}$, and GPS scintillation index $S_{4}$ during March 1 (day 60)-April 30 (day 120), 2003. Daily variation in $S_{4}$ averaged over 1900-2300 LT is also plotted by white curve. Vertical line in $T_{\mathrm{bb}}$ plot indicates the longitude of Kototabang $\left(100.32^{\circ} \mathrm{E}\right)$. Black portions in $S_{4}$ plot denote the absence of observations due to instrumental problems.

\section{Observations and Analysis \\ 2.1 GPS scintillation observations}

In January 2003, we started to monitor ionospheric scintillations at Kototabang by means of three spaced 1.5754GHz GPS receivers located with baseline distances of 116, 127 and $152 \mathrm{~m}$. Our aim is to measure the drift velocity of FAIs (Ogawa et al., 2006; Otsuka et al., 2006). The scintillation magnitude is represented by the index $S_{4}$ that is defined as the normalized standard deviation of signal intensity, i.e. $S_{4}^{2}=\left(\left\langle I^{2}\right\rangle-\langle I\rangle^{2}\right) /\langle I\rangle^{2}$, where $I$ is the signal intensity, and the angle brackets denote the ensemble average of the enclosed quantity. $S_{4}$ was calculated every $10 \mathrm{~min}$ by using data from one of the receivers that provide signal intensity with a sampling rate of $20 \mathrm{~Hz}(50 \mathrm{~ms})$. When signals from multiple GPS satellites were simultaneously received, the highest $S_{4}$ of all the $S_{4}$ values was selected. The $S_{4}$ data with satellite elevation angles $\geq 30^{\circ}$ were used to determine the scintillation occurrence within the circular area, covering the geomagnetic latitudes between $4^{\circ}$ and $13^{\circ} \mathrm{S}$, with a radius of $520 \mathrm{~km}$ at $300 \mathrm{~km}$ altitude over Kototabang (see Fig. 3).

Figure 1 shows $S_{4}$ variations from January 2003 to June 2007 in day-local time coordinates. The $S_{4}$ values less than about 0.2 originate from radio interference, receiver noise, etc. and, therefore, should be disregarded. The vertical black portions represent the absence of data due to instrumental problems, which happened sporadically. Such problems, however, do not detect from the following discussion on the scintillation activity characteristics. Figure 1 indicates the following: (1) scintillation activity clearly decreases with decreasing solar activity from 2003 to 2007; (2) scintillations appear predominantly in equinoctial months, i.e. in March-April and SeptemberOctober, and mostly between near local sunset ( 2000 LT; $\mathrm{LT}=\mathrm{UT}+7 \mathrm{~h}$ at Kototabang) and $0100 \mathrm{LT}$ in March-April and between 2000 and 2300 LT in September-October; (3) scintillation occurrences show clear day-to-day variability and are more frequent in March-April than SeptemberOctober. Plasma bubbles imaged by an all-sky camera are known to appear between sunset and later hours after midnight, while the GPS scintillations disappear at around midnight, as shown in Fig. 1: the latter fact means that the 350$\mathrm{km}$ scale electron density irregularities causing the scintillations disappear after midnight. Thus, Fig. 1 can be regarded as a proxy of the plasma bubble occurrences before midnight over Kototabang. Since the bubbles near Kototabang are generated near the sunset terminator and then move eastward at about $100^{-1}$ (Yokoyama et al., 2004; Fukao et al., 2006; Otsuka et al., 2006), the scintillations at earlier local times are believed to be generated at locations closer to Kototabang.

\subsection{Comparison between scintillations and tropo- spheric disturbances}

A number of physical processes are responsible for causing the GPS scintillation activity shown in Fig. 1. One of these may be tropospheric disturbances in the equatorial region, which launch atmospheric waves that propagate upward toward the ionosphere. In this paper, as a measure of tropospheric disturbances, we use black body temperature $\left(T_{\mathrm{bb}}\right)$ (often called the "cloud-top temperature") of the Earth inferred from Outgoing Long wave Radiation (OLR) data that were continuously monitored at 1 -h intervals from geostationary meteorological satellites (GMS-5 before 21 May 2003 and GOES-9 after 22 May 2003). In general, lower (higher) $T_{\mathrm{bb}}$ indicates the cloud top altitude to be higher (lower) because of more (less) active tropospheric convection. It has been pointed out that AGWs inducing ionospheric plasma disturbances may be launched upward from active convection regions in the troposphere (e.g., Röttger, 1977, 1981; Hocke and Tsuda, 2001; Tsuda and Hocke, 


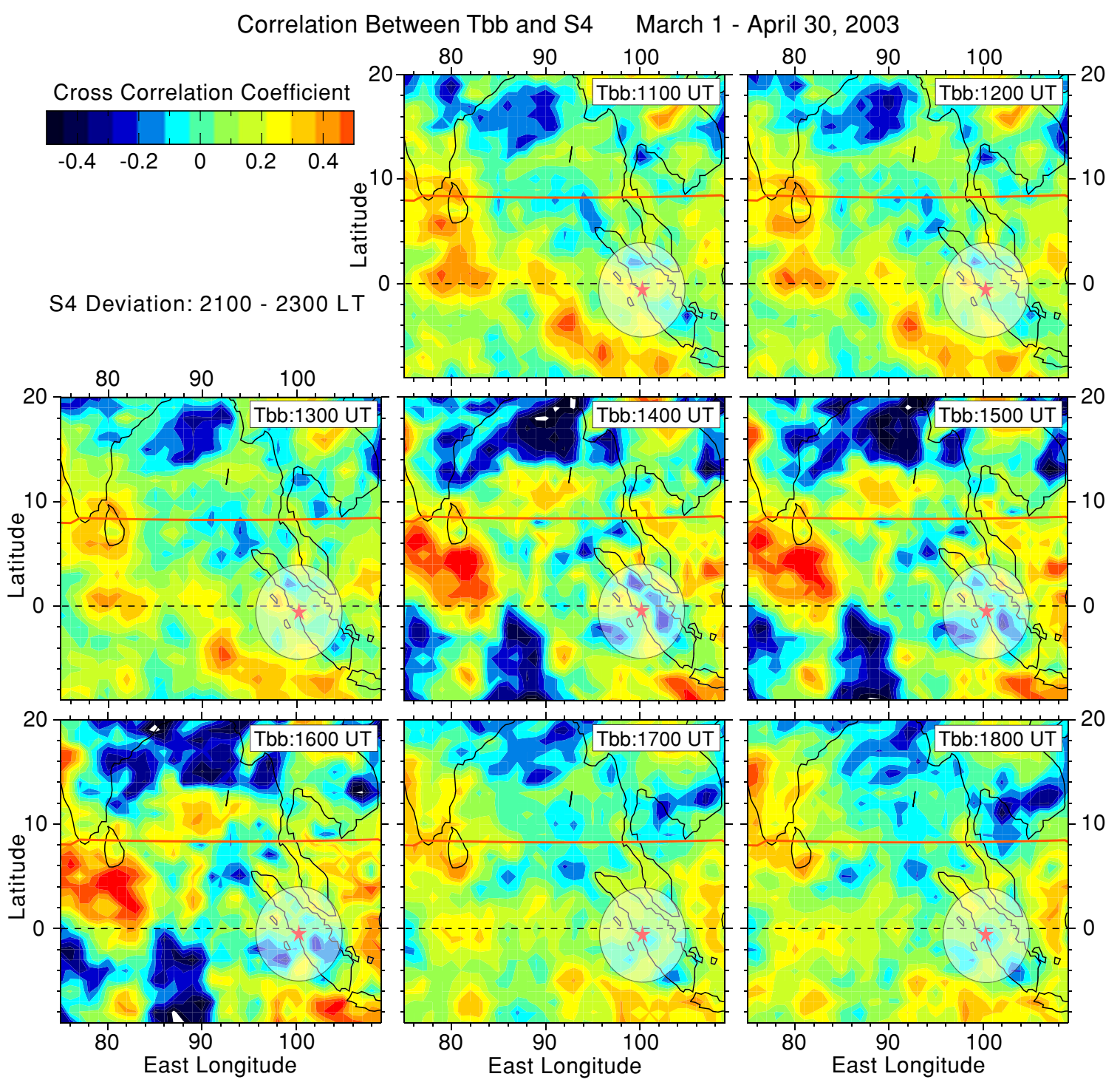

Fig. 3. Time variation of cross-correlation coefficients between $S_{4}$ and $T_{\mathrm{bb}}$. In calculating coefficients, $S_{4}$ deviated from the average over $2100-2300$ LT and March 1-April 30, 2003, and hourly $T_{\mathrm{bb}}$ deviated from the average over March 1-April 30, 2003 are used. GPS scintillation data were obtained within the circular area with a radius of $520 \mathrm{~km}$ at $300 \mathrm{~km}$ altitude over Kototabang ( $\star$ ), which corresponds to a satellite elevation angle of $\geq 30^{\circ}$, are used to calculate $S_{4}$. The geomagnetic equator at about $9^{\circ} \mathrm{N}$ is indicated by the horizontal red line.

2004). Tsuda et al. (2000) and Tsuda and Hocke (2004) showed that AGW energy in the stratosphere inferred from GPS/Meteorology data is enhanced, in particular, over Indonesia where $T_{\mathrm{bb}}$ is low (cold).

As an example, Fig. 2 shows daily variations of $S_{4}$ at Kototabang and $T_{\mathrm{bb}}$ during March 1 (day 60)-April 30 (day 120), 2003. Note that a similar figure also appears in Fig. 6 of Ogawa et al. (2006). The $T_{\mathrm{bb}}$ plot covers longitudes between $70^{\circ}$ and $102^{\circ} \mathrm{E}$ (Kototabang longitude $=100.32^{\circ} \mathrm{E}$ ).

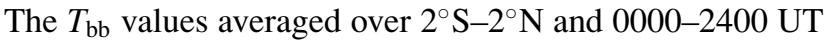
are plotted in the figure. In the $T_{\mathrm{bb}}$ plot the cloud clusters with low temperature move eastward, and the organized temperature structures over the Indian Ocean are often disturbed at around $100^{\circ} \mathrm{E}$ near Kototabang due to high mountains in Sumatra. It can be observed that when the scintillations occur between 2000 and $0000 \mathrm{LT}$, the $T_{\mathrm{bb}}$ values are higher than, say, $270 \mathrm{~K}$ somewhere between $70^{\circ}$ and $95^{\circ} \mathrm{E}$ : for example, the scintillations on days 67-76, 81, 95-99 and $102-104$ are correlated to high $T_{\mathrm{bb}}$ at $80^{\circ}-96^{\circ} \mathrm{E}$. However, this is not always true for other scintillation events; the $T_{\mathrm{bb}}$ values for the scintillations on days 83-84 and 119 are low everywhere, and those for the scintillations on days 92-93 are high at $70^{\circ}-82^{\circ} \mathrm{E}$ but low at $82^{\circ}-98^{\circ} \mathrm{E}$.

To know quantitative relations between $S_{4}$ and $T_{\mathrm{bb}}$, crosscorrelation coefficients $(R)$ between the two parameters were calculated. For these calculations we used the $S_{4}$ values deviated from the average over 2100-2300 LT and March 1-April 30, 2003, and the hourly $T_{\mathrm{bb}}$ values deviated from the average over the same days. The results are displayed in Fig. 3. As described above, the scintillation data obtained within the circular area with a radius of $520 \mathrm{~km}$ at $300 \mathrm{~km}$ altitude over Kototabang, which corresponds to a satellite elevation angle of $\geq 30^{\circ}$, were adopted to calculate $S_{4}$. The high positive (red) and negative (blue) $R$ values exceeding \pm 0.45 appear predominantly in the $1400-1600$ UT panels. A high positive $R$ area exists at latitudes of $0^{\circ}-10^{\circ} \mathrm{N}$ and longitudes of $75^{\circ}-82^{\circ} \mathrm{E}$, while high negative $R$ areas occur between $80^{\circ}$ and $100^{\circ} \mathrm{E}$ to the north and the south of the 

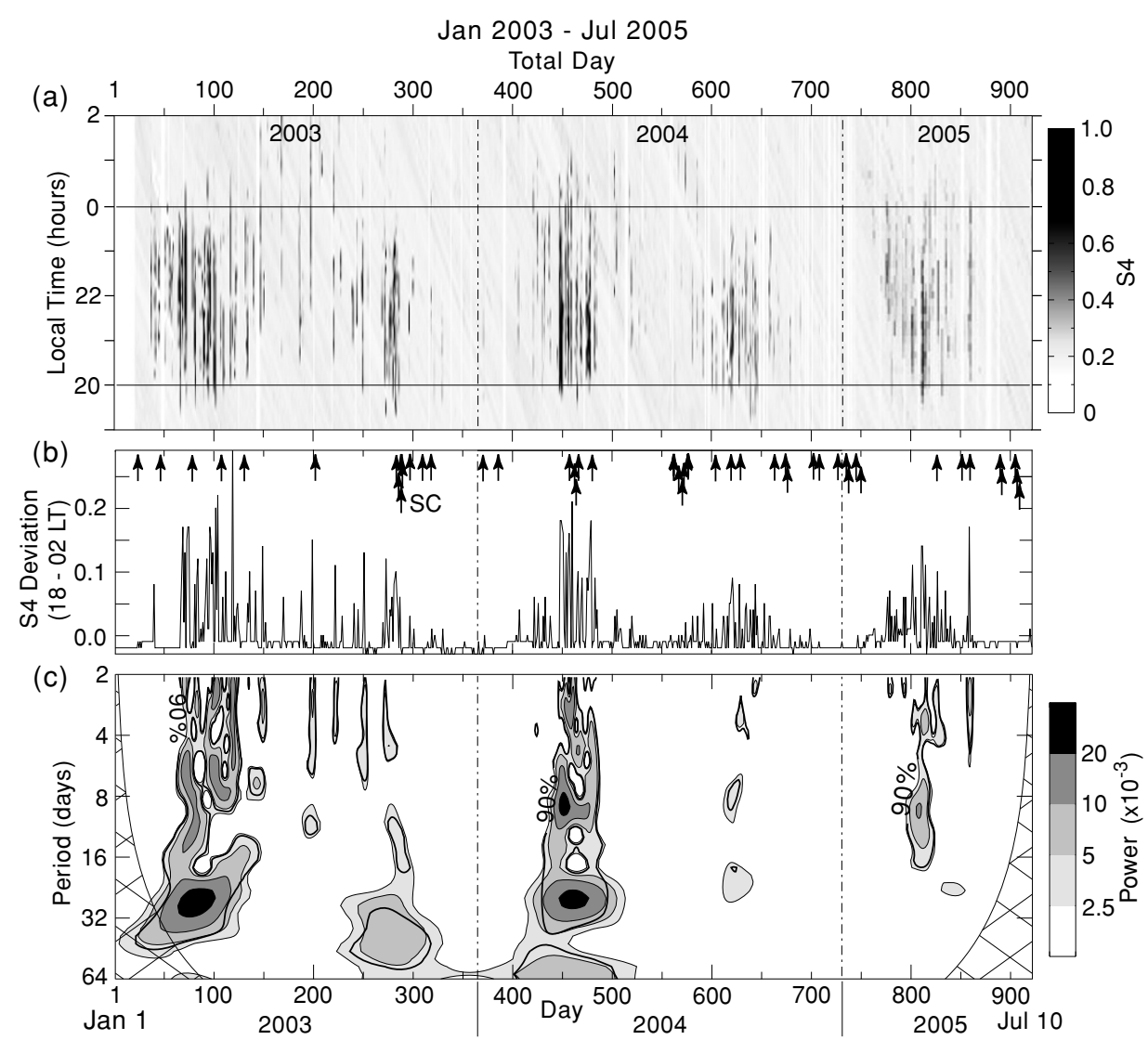

Fig. 4. (a) Day-local time variations of $S_{4}$ during January 2003-July 2005 (see Fig. 1). (b) Daily variation of $S_{4}$ deviated from average over 1800-0200 LT and 920 days is plotted. Geomagnetic storm commencement (SC) is marked by arrow. (c) Wavelet power spectra of $S_{4}$ variation shown in (b). $90 \%$ confidence level is shown by thick solid curve. Spectra within cross-hatched areas are unreliable.

high positive $R$ area. Note that $R$ is positive when both $S_{4}$ and $T_{\mathrm{bb}}$ are high or low, while it is negative when one is high and the other is low, which means that for high (low) $S_{4}, T_{\mathrm{bb}}$ at the red areas are high (low), and $T_{\mathrm{bb}}$ at the blue areas are low (high). One of the possible reasons why the red and blue areas are clearly separated in latitude is as follows: when the tropospheric convection is active (accordingly, low $T_{\mathrm{bb}}$ ) at latitudes of $0^{\circ}-10^{\circ} \mathrm{N}$ and longitudes of $75^{\circ}-82^{\circ} \mathrm{E}$, the convection at $80^{\circ}-100^{\circ} \mathrm{E}$ to the north and the south of $0^{\circ}-10^{\circ} \mathrm{N}$ becomes inactive (high $T_{\mathrm{bb}}$ ) because of meridional circulation from the active region to the inactive regions. In any case, Fig. 3 suggests that the scintillation occurrences over Kototabang before midnight can be related to the tropospheric disturbances (high and low $T_{\mathrm{bb}}$ ) mainly over the Indian Ocean to the west of Kototabang.

\subsection{Wavelet analysis of $S_{4}, T_{b b}$ and lower thermo- sphere wind}

To determine the spectral components of the $T_{\mathrm{bb}}$ and $S_{4}$ variations, we made a wavelet analysis of both parameters. Figure 4(a) shows day-local time variations of $S_{4}$ during January 2003-July 2005 (see Fig. 1). The daily variation of $S_{4}$ deviated from average over 1800-0200 LT and 920 days is displayed in Fig. 4(b), where geomagnetic storm commencement (SC) is marked by a vertical arrow. Although some geomagnetic storms might induce GPS scintillations, we think that as shown in Fig. 4(b), the association between the SC and scintillation occurrences in equinoctial months is poor. Figure 4(c) shows wavelet power spectra of the $S_{4}$ variation (Fig. 4(b)) in day-period coordinates. A 90\% confidence level is shown by the thick solid curve. The spectra within the cross-hatched areas are unreliable because of an insufficient amount of the data. Some spectral peaks having periods between 2 and 30 days can be clearly seen in equinoctial months in which the scintillations are highly activated. The $S_{4}$ spectra in equinoctial months in 2003 and 2004 are enlarged in Fig. 5. In March-April 2003 (Fig. 5(a)) some spectral peaks appear between the 2- and 15-day period and a peak at around 24-day period. The spectral peaks between the 2- and 10-day period and at around the 24-day period are observed in March-April 2004 (Fig. 5(c)). Similar spectral peaks with weak power are also discerned in September-October 2003 (Fig. 5(b)) and 2004 (Fig. 5(d)).

Next we compare wavelet periods among $S_{4}$, neutral winds in the lower thermosphere and $T_{\mathrm{bb}}$. The neutral winds were measured with a meteor radar at Kototabang. In brief, this radar is operated at $37.7 \mathrm{MHz}$ with an output power of $12 \mathrm{~kW}$ and estimates horizontal wind velocities at an altitudes of 80-102 km with time and altitude resolutions of $1 \mathrm{~h}$ and $2 \mathrm{~km}$, respectively (Sridharan et al., 2006). Only zonal winds are examined in this paper. First, using hourly zonal wind data at a certain altitude, deviations from the 1-day average were obtained. Second, the deviations were processed to calculate a time variation of the wind component $\left(u^{\prime}\right)$ with certain periods (2-8 and $2-24 \mathrm{~h}$ in our case). Finally, the squared wind component $\left(u^{\prime 2}\right)$ was averaged over 1 day to know the daily variance $\left(\overline{u^{\prime 2}}\right)$ of the zonal wind. 

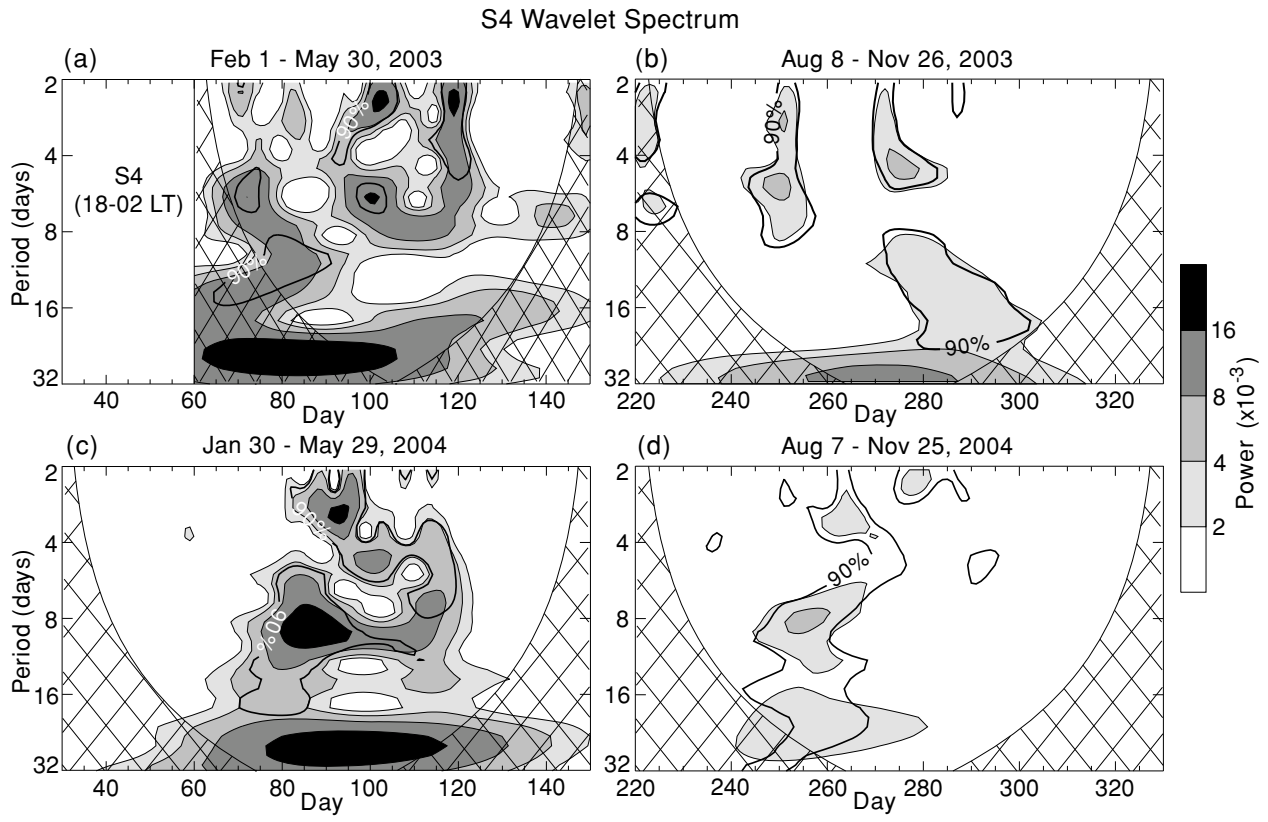

Fig. 5. Wavelet power spectra of $S_{4}$ in four seasons. (a) February 1-May 30, 2003, (b) August 8-November 26, 2003, (c) January 30-May 29, 2004 and (d) August 7-November 25, 2004. 90\% confidence level is shown by thick solid curve.

(a) Jan 30 - May 30, 2003

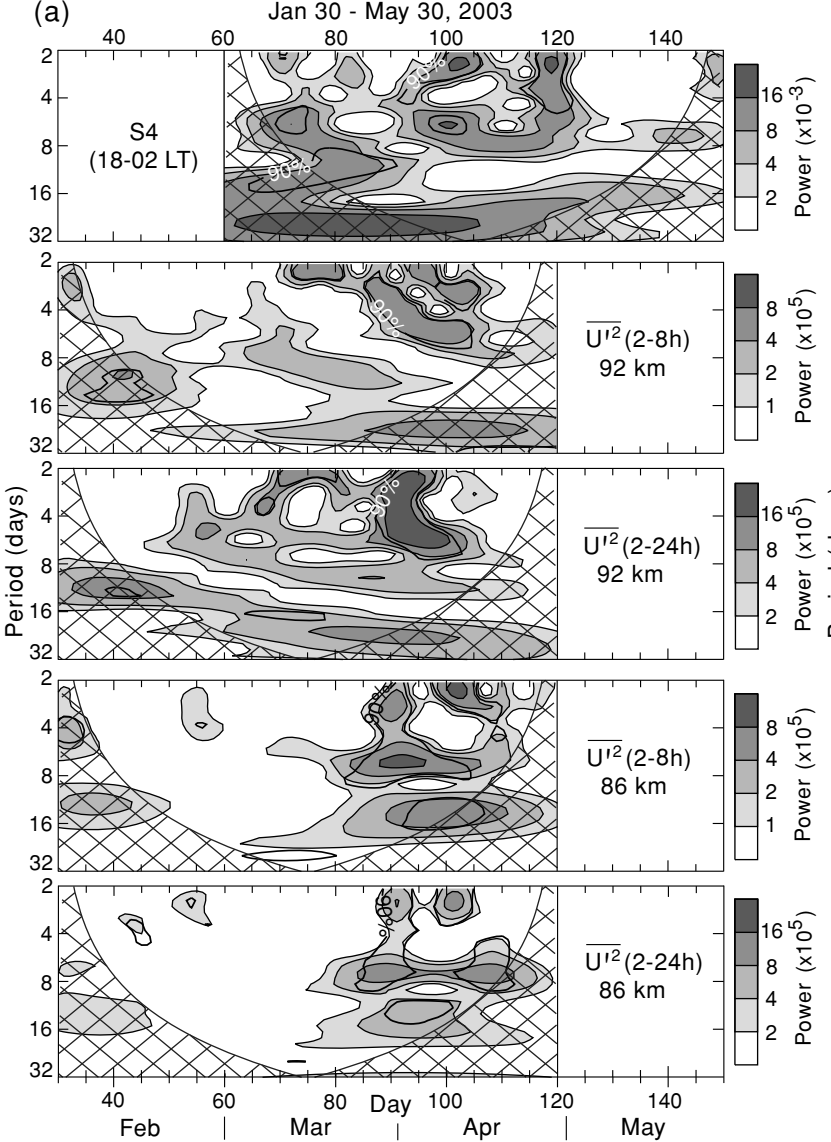

(b)

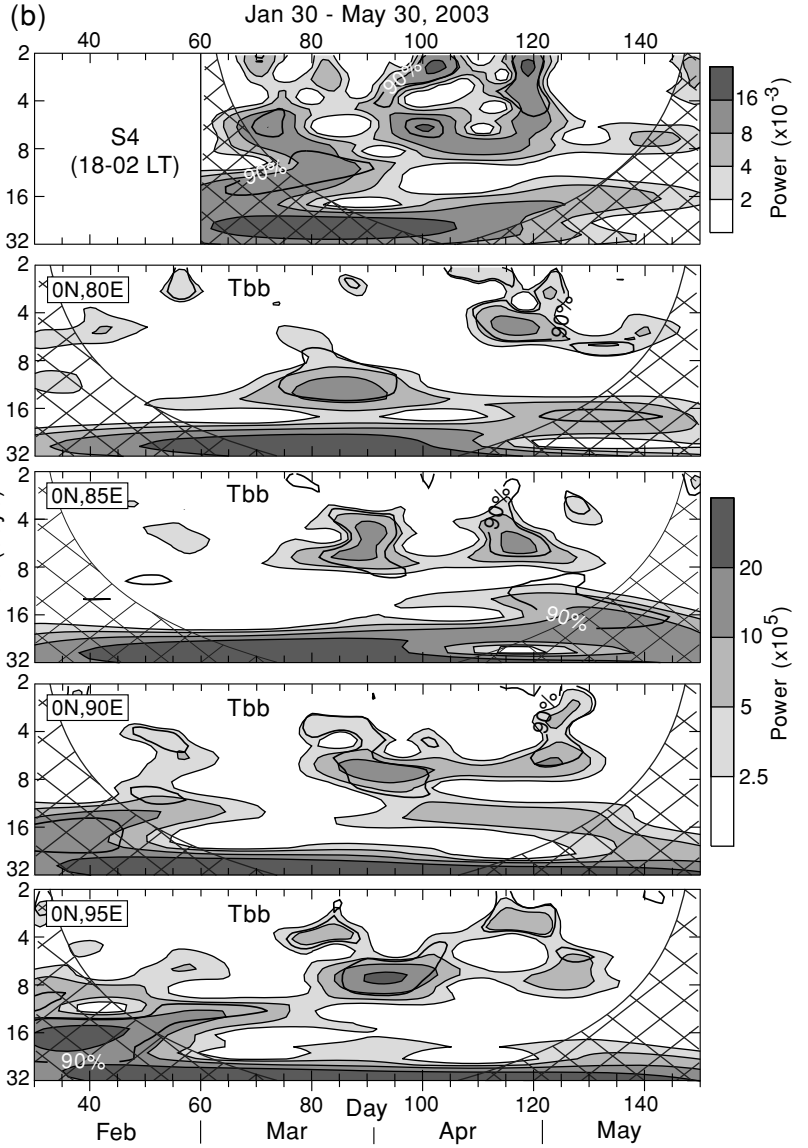

Fig. 6. Wavelet power spectra during January 30-May 30, 2003. (a) $S_{4}$ and $\overline{u^{\prime 2}}$ with periods of $2-8$ and $2-24 \mathrm{~h}$ at altitudes of 92 and $86 \mathrm{~km}$. (b) $S_{4}$ and $T_{\text {bb }}$ at $\left(0^{\circ} \mathrm{N}, 80^{\circ} \mathrm{E}\right),\left(0^{\circ} \mathrm{N}, 85^{\circ} \mathrm{E}\right),\left(0^{\circ} \mathrm{N}, 90^{\circ} \mathrm{E}\right)$, and $\left(0^{\circ} \mathrm{N}, 95^{\circ} \mathrm{E}\right) .90 \%$ confidence level is shown by the thick solid curve.

Figure 6(a) shows wavelet spectra of $S_{4}$ and $\overline{u^{\prime 2}}$ with periods of 2-8 and 2-24 h at altitudes of 92 and $86 \mathrm{~km}$ during January 30-May 30, 2003. Note that no data of $S_{4}$ and $\overline{u^{\prime 2}}$ were obtained before day 60 and after day 120 , respectively.
During days $60-120$, the spectral peaks existing between the 2- and 15-day period and at around the 24-day period in $S_{4}$ are also discerned in the $\overline{u^{\prime 2}}$ spectra: in detail, the $S_{4}$ peaks between the 2- and 24-day period during days 65-90 

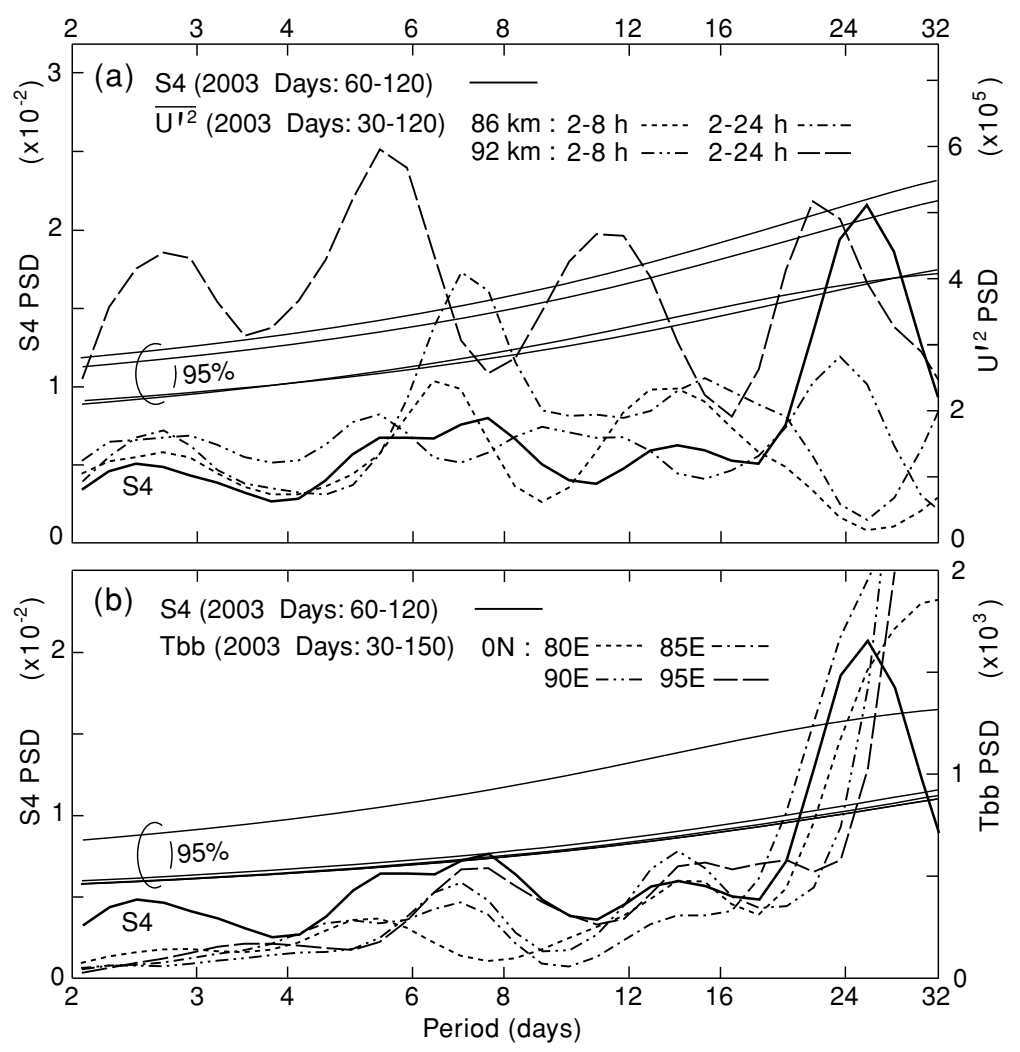

Fig. 7. Periodgrams of $S_{4}, T_{\mathrm{bb}}$ and $\overline{u^{\prime 2}}$ with periods of $2-8$ and $2-24 \mathrm{~h}$ at altitudes of 92 and $86 \mathrm{~km}$ for wavelet power spectra shown in Fig. 6. $95 \%$ confidence level of each power spectral density (PSD) is shown by thin solid curve.

correspond well to the $\overline{u^{\prime 2}}$ peaks at $92 \mathrm{~km}$ altitude during the same days, and the $S_{4}$ peaks between 2 - and 8-day period during days $90-120$ are also seen in the $\overline{u^{\prime 2}}$ peaks at altitudes of 86 and $92 \mathrm{~km}$ during the same days. Figure 6(b) compares the wavelet spectra of $S_{4}$ with $T_{\mathrm{bb}}$ spectra at the equator $\left(0^{\circ} \mathrm{N}\right)$ at four longitudes $\left(80^{\circ}, 85^{\circ}, 90^{\circ}\right.$ and $\left.95^{\circ} \mathrm{E}\right)$ to the west of Kototabang. Some spectral peaks appearing between the 3-and 16-day period in the $T_{\mathrm{bb}}$ spectra are also discerned in the $S_{4}$ spectra.

Figure 7 shows periodgrams of $S_{4}, T_{\mathrm{bb}}$ and $\overline{u^{\prime 2}}$ for the wavelet power spectra shown in Fig. 6. The smooth thin solid curves represent the $95 \%$ confidence level of the power spectral density (PSD). The $S_{4}$ and $\overline{u^{\prime 2}}$ periodgrams in Fig. 7(a) exhibit spectral peaks at periods of about 2.5, $5,8,14$ and 25 days, and of about 2.5, 5, 7, 12-16 and 22-25 days, respectively. The $T_{\mathrm{bb}}$ periodgrams in Fig. 7(b) have peaks at periods of about 5, 7 and 14 days. It is found from Fig. 7 that some predominant periods seen in $S_{4}$ have counterparts in $\overline{u^{\prime 2}}$ and $T_{\mathrm{bb}}$, and that some predominant periods appearing in $T_{\mathrm{bb}}$ do not always have counterparts in $\overline{u^{\prime 2}}$ and $S_{4}$. Similar wave periods are also discerned more or less in the seasons shown in Figs. 5(b), 5(c) and 5(d) (not shown). Thus, Figs. 6 and 7 suggest that the waves with periods longer than 5 days, may be generated in the troposphere, can propagate upward to the lower thermosphere (92 km altitude) and may reach the ionosphere where the GPS scintillations originate. Note that the normal mode Rossby waves have periods of 2, 5, 10 and 16 days (e.g., Forbes, 1996). Since several spectral peaks of the $S_{4}$ and $\overline{u^{\prime 2}}$ fluctuations have periods similar to these waves, they may be attributed to the upward propagation of PWs.

\section{Simulation of Equatorial Atmospheric Waves}

In Section 2, we have analyzed the data of $S_{4}$ (GPS scintillation index), $\overline{u^{\prime 2}}$ (variance of zonal wind) at altitudes of 86 and $92 \mathrm{~km}$ and $T_{\mathrm{bb}}$ (Earth's black body temperature) to find that these parameters fluctuate with planetary-scale wave periods. However, it is very difficult to verify the existence of such waves at ionospheric altitudes from our observational data. To determine the behavior of neutral winds in terms of PWs and AGWs that modulate them, we conducted numerical simulations using the Kyushu University General Circulation Model (KUGCM): see Miyoshi and Fujiwara (2006, 2008) and Miyoshi (2006) for details. In brief, the KUGCM is a global spectral model with a triangular truncation of T85 (T21), which is equivalent to a grid spacing of $1.4^{\circ}\left(5.6^{\circ}\right)$ in latitude and longitude for a high (low) resolution model. The low-resolution model was used only to examine PWs with global scales. The region from the ground surface to about $500 \mathrm{~km}$ altitude is divided into 75 vertical levels with a resolution of $0.4 \times$ (atmospheric scale height) above the tropopause; i.e., the resolution is about $2,8,12$ and $17 \mathrm{~km}$ at 100, 150, 200 and $300 \mathrm{~km}$ altitude, respectively. The KUGCM includes a full set of the physical processes appropriate for the troposphere, stratosphere, mesosphere and thermosphere, as well as schemes for hydrology, a boundary layer, radiation, eddy diffusion and moist convection. It also includes cumulus and gravity wave parameterizations, effects of the surface topography, among others. In the thermosphere the neutral composition is ob- 

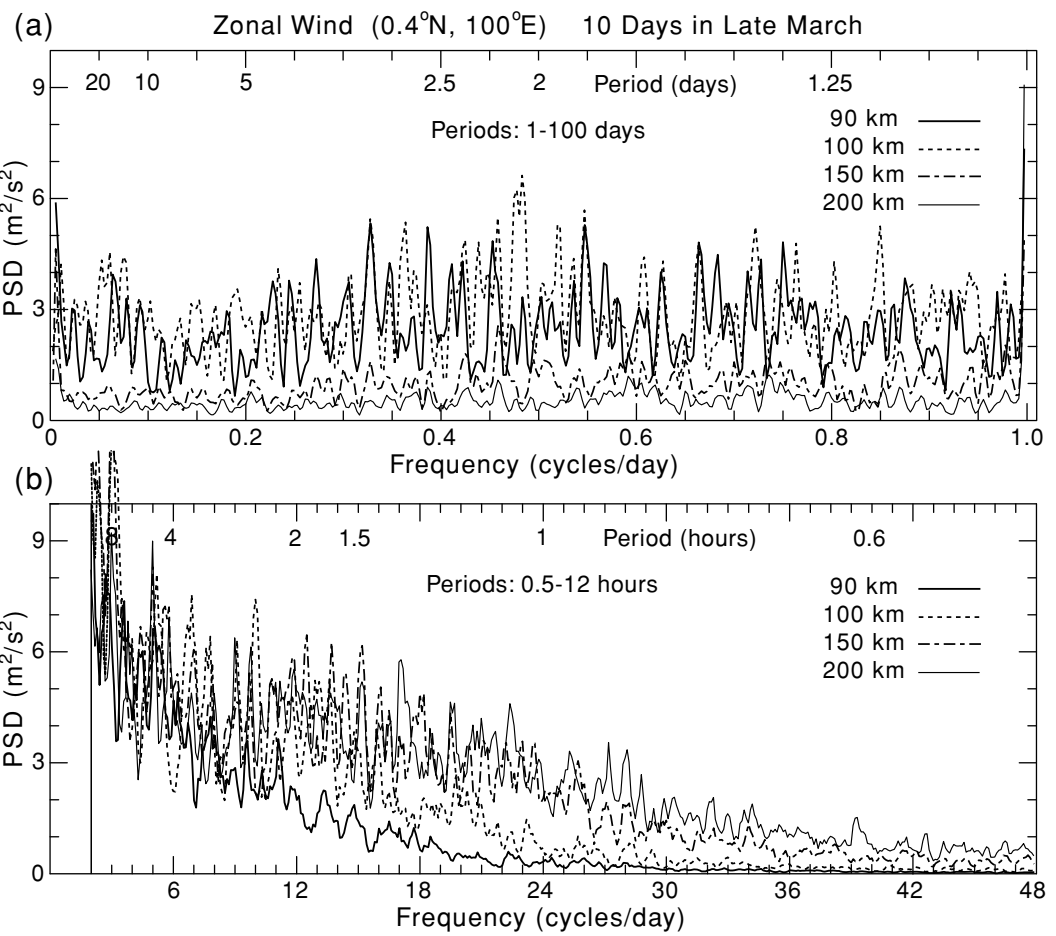

Fig. 8. Frequency spectra of zonal wind with periods of (a) 1-100 days and (b) $0.5-12 \mathrm{~h}$ at four altitudes simulated by high resolution KUGCM. 1- and 0.5 -day winds are not shown because of their strong power. Simulation data at $\left(0.4^{\circ} \mathrm{N}, 100^{\circ} \mathrm{E}\right)$ for 10 days in late March are used.

tained by solving the continuity equation for major species $\left(\mathrm{N}_{2}, \mathrm{O}_{2}\right.$ and $\left.\mathrm{O}\right)$, and infrared cooling, absorption of solar EUV and UV, ion drag, Joule heating and molecular diffusion are taken into account. A global electron density distribution model is also used. To exclude the effects of day-to-day variations of solar EUV and UV fluxes and geomagnetic activity, the simulations were conducted under solar cycle minimum and geomagnetically quiet conditions. In this paper, we discuss only zonal winds and waves because these seem to be important for the seeding of plasma bubbles (e.g., Farley et al., 1986).

\subsection{Frequency spectrum of atmospheric waves}

Figure 8 displays frequency spectra of the zonal wind with periods of 1-100 days (Fig. 8(a)) and 0.5-12 h (Fig. 8(b)) at four altitudes from 90 to $200 \mathrm{~km}$, which are calculated from the high resolution $\left(1.4^{\circ}\right) \mathrm{KUGCM}$ data at $\left(0.4^{\circ} \mathrm{N}, 100^{\circ} \mathrm{E}\right)$ for 10 days in late March. In Fig. 8(a), the waves with periods longer than $\sim 1$ day dissipate quickly above $100 \mathrm{~km}$ and cannot propagate upward beyond $150 \mathrm{~km}$. Contrary to this, the PSD of the $0.5-$ to 3-hour waves in Fig. 8(b) increase with increasing altitude. The simulations indicate that these short-period waves can propagate up to $400 \mathrm{~km}$ (see Figs. 11 and 12).

To determine the detailed characteristics of the winds shown in Fig. 8(a), Fig. 9 displays power spectra of the eastward and westward propagating waves with periods longer than 2 days at three altitudes in frequency-wave number coordinates, which have been obtained from the lowresolution $\left(5.6^{\circ}\right) \mathrm{KUGCM}$ data at $\left(2.8^{\circ} \mathrm{N}, 0^{\circ}-360^{\circ} \mathrm{E}\right)$ for 1 year. Note that the spectral peaks at around zero frequency are due to seasonal/1-year variations of the waves. The waves with periods of 2-20 days dissipate above $125 \mathrm{~km}$ altitude, as stated above (Fig. 8(a)). Several spectral peaks can be observed below $125 \mathrm{~km}$ : the predominant ones are eastward propagating Kelvin waves with a 2-day period with zonal wave numbers $K=+1-+3$ and westward propagating PWs with 6-day period with $K=-1$. The other waves are PWs with a 4-day period with $K=-2$, with 5-, 10- and 16-day periods with $K=-1$ and with 2- to 2.5-day periods with $K=-3$ to -4 . Note that the $S_{4}$ periodgram in Fig. 7 indicates the spectral peaks at periods of about 2.5, $5,8,14$ and 25 days, which are partly consistent with the simulation results.

3.2 Time and altitude variations of atmospheric waves

In this subsection we examine time and altitude variations of the equatorial wind simulated by the highresolution $\left(1.4^{\circ}\right) \mathrm{KUGCM}$. Figure 10 shows time variations of zonal winds at $\left(0.4^{\circ} \mathrm{N}, 80^{\circ} \mathrm{E}\right),\left(0.4^{\circ} \mathrm{N}, 90^{\circ} \mathrm{E}\right)$ and $\left(0.4^{\circ} \mathrm{N}\right.$, $\left.100^{\circ} \mathrm{E}\right)$ at five altitudes from 150 to $350 \mathrm{~km}$ during $48 \mathrm{~h}$ in March 23-24. The winds fluctuate with time due to the waves with periods of about $1-24 \mathrm{~h}$. It is seen that the zonal winds above $200 \mathrm{~km}$ altitude are, as a whole, eastward after local sunset $(\sim 1900$ LT) until sunrise $(\sim 0600$ LT), with a maximum of about $80^{-1}$ near midnight, and westward in the daytime with a maximum of about $80^{-1}$ near noon. Such behavior is mainly caused by a diurnal tide excited in the thermosphere.

As shown in Fig. 8(b), the winds with periods of $0.5-$ $12 \mathrm{~h}$ become more evident with increasing altitude. In order to see the behavior of the short-period AGWs between 1040 UT (1740 LT at Kototabang) and 1600 UT (2300 LT), Fig. 11 displays time variation in the zonal wind with periods of $1-4 \mathrm{~h}$ at $0.4^{\circ} \mathrm{N}$ during $1040-1600$ UT (17402300 LT) on March 21 in longitude-altitude coordinates, which are simulated by the high resolution KUGCM. The solid (dotted) line contours indicate on eastward (westward) 

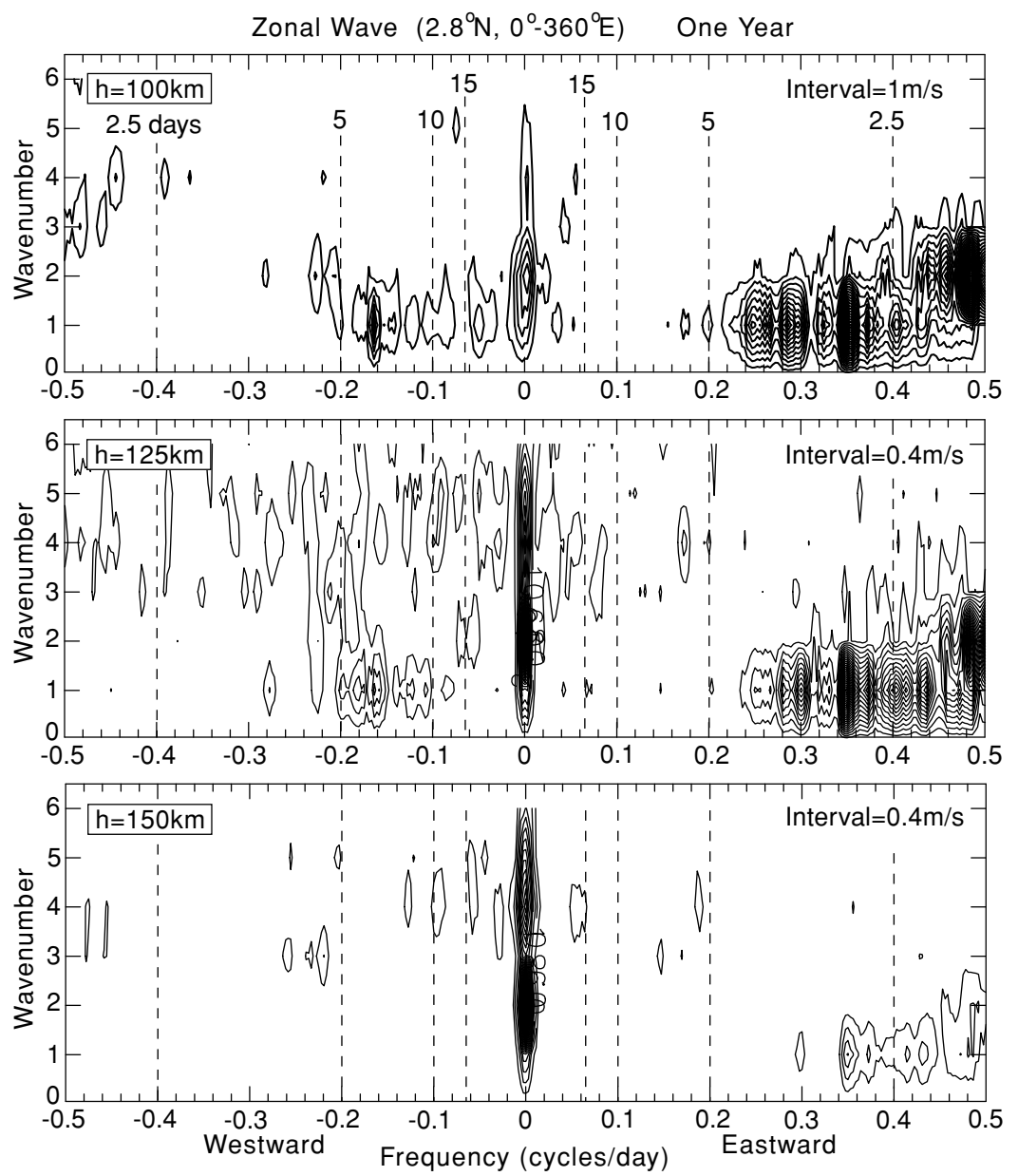

Fig. 9. Power spectra of eastward and westward propagating waves (periods $\geq 2$ days) at three altitudes in frequency-wave number coordinates simulated by low-resolution KUGCM. Simulation data at $\left(2.8^{\circ} \mathrm{N}, 0^{\circ}-360^{\circ} \mathrm{E}\right)$ for 1 year are used. Spectral peaks at around zero frequency are due to seasonal/1-year variations of waves.

wind. Note that in the simulations the longitudinal resolution is about $150 \mathrm{~km}$ and the altitudinal one changes from $2 \mathrm{~km}$ at $100 \mathrm{~km}$ altitude to $17 \mathrm{~km}$ at $300 \mathrm{~km}$ altitude (see above). At altitudes of around 120-300 km, both eastward and westward wind areas have scale lengths of about 300$1000 \mathrm{~km}$ (about $3^{\circ}-10^{\circ}$ width) in longitude and about 30 $100 \mathrm{~km}$ in altitude. They move, as a whole, eastward at about $100^{-1}$ while changing the area patterns with time, in line with the results shown in Fig. 10. The velocities within the areas also change with time, with maximum eastward and westward wind velocities of about $100^{-1}$. The wind structures seen in Fig. 11 change day by day. Figure 12 shows time variations of the zonal winds with periods of 1$4 \mathrm{~h}$ between 1400 UT and 1520 UT on March 21-23. The structures and their eastward movement seen on March 21 (Fig. 11) are also discerned on March 22 and 23. The structures are more ordered on March 22 and 23 than March 21, and the wind velocities above $150 \mathrm{~km}$ altitude are fastest on March 22. Thus, Figs. 11 and 12 demonstrate that the activity of the short-period AGWs in the equatorial thermosphere above $120 \mathrm{~km}$ altitude are changeable with time and day. It is noted that the wavy structures in the thermosphere above $120 \mathrm{~km}$ altitude in Figs. 11 and 12 stem mainly from the ion drag and molecular viscosity, which also affect the upward propagation of PWs.

\section{Summary and Discussion}

The results can be summarized as follows:

(1) 4.5-year observations of equatorial GPS scintillations associated with plasma bubbles indicate that scintillation activity clearly decreases with decreasing solar activity from 2003 to 2007 . Scintillations appear predominantly in equinoctial months, i.e. in MarchApril and September-October, and between 2000 and 0100 LT in March-April and between 2000 and 2300 LT in September-October. Scintillation occurrences show clear day-to-day variability and appear more often in March-April than September-October.

(2) Day-to-day comparison between $S_{4}$ and $T_{\mathrm{bb}}$ shows that the scintillation occurrence can be related to $T_{\mathrm{bb}}$ variation over the Indian Ocean to the west of Kototabang. Calculations of two-dimensional cross-correlation coefficients $(R)$ between $S_{4}$ and $T_{\mathrm{bb}}$ indicate high positive and negative $R$ values exceeding \pm 0.45 appearing mainly at 1400-1600 UT (2100-2300 LT at Kototabang) at some localized areas (see Fig. 3). This result suggests that the scintillation occurrences before midnight can be related, more or less, to the tropospheric disturbances over the Indian Ocean. 


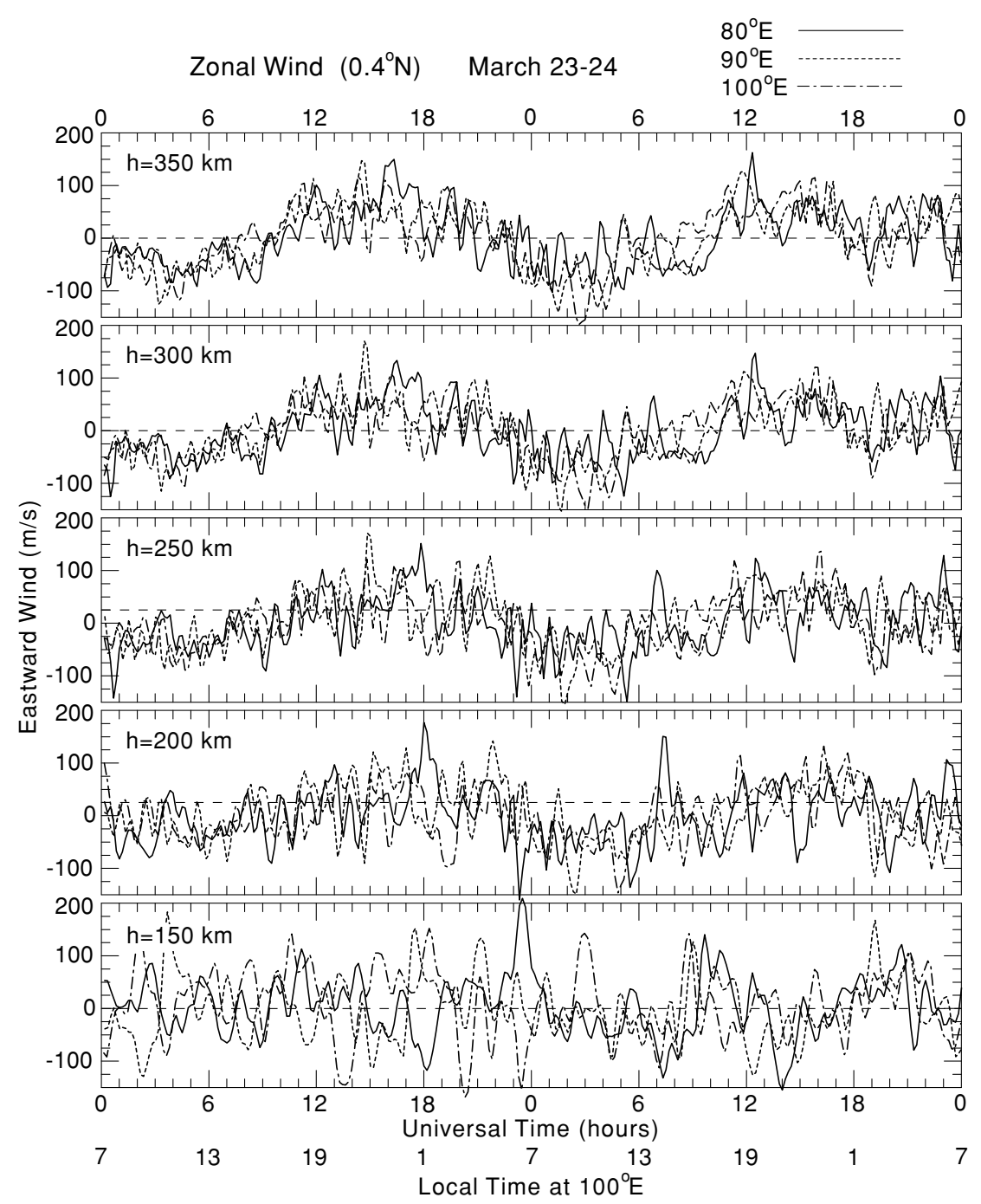

Fig. 10. Time variations of zonal winds at $\left(0.4^{\circ} \mathrm{N}, 80^{\circ} \mathrm{E}\right),\left(0.4^{\circ} \mathrm{N}, 90^{\circ} \mathrm{E}\right)$ and $\left(0.4^{\circ} \mathrm{N}, 100^{\circ} \mathrm{E}\right)$ at five altitudes during March $23-24$ simulated by high-resolution KUGCM.

(3) Wavelet analyses of $S_{4}, \overline{u^{\prime 2}}$ and $T_{\mathrm{bb}}$ to determine the reasons of the day-to-day variability of the scintillation activity indicate the following (1) $S_{4}$ wavelet spectra exhibit some spectral peaks between the 2- and 15day period and a peak at around the 24-day period. (2) Similar periods are also discerned in $\overline{u^{\prime 2}}$ spectra. Some spectral peaks appearing between the 3- and 16day period in $T_{\mathrm{bb}}$ are also recognized in $S_{4}$. (3) In detail, wavelet periodgrams of $S_{4}$ and $\overline{u^{\prime 2}}$ exhibit spectral peaks at periods of about $2.5,5,8,14$ and 25 days, and of about $2.5,5,7,12-16$ and 22-25 days, respectively. $T_{\mathrm{bb}}$ periodgrams have peaks at periods of about 5, 7, and 14 days. These results suggest that longperiod ( $\geq 2$ days) atmospheric waves, i.e. planetaryscale waves, are responsible for the $\overline{u^{\prime 2}}$ and $S_{4}$ fluctuations.

(4) To determine the behavior of neutral winds in terms of PWs and short-period AGWs in the equatorial thermosphere, we conducted numerical simulations using KUGCM. The results indicate the following (1) 2- to 20-day waves dissipate rapidly above about $125 \mathrm{~km}$, being unable to propagate upward further, and 0.5 - to 3-h waves become predominant with increasing altitude beyond $100 \mathrm{~km}$. (2) Below $125 \mathrm{~km}$, westward propagating PWs exist with a period of 4 days (zonal wave number $K=-2$ ) and 5-6, 10 and 16 days $(K=-1)$ in addition to 2 - to 2.5 -day waves $(K=-3$ to -4$)$, and eastward propagating Kelvin waves exist with periods of $2-5$ days $(K=+1-+2)$. Figure 7 indicates the $S_{4}$ spectral peaks at periods of about 2.5, 5, 8,14 and 25 days, which are partly consistent with the simulation results. (3) Zonal winds above $200 \mathrm{~km}$ altitude at $80^{\circ}-100^{\circ} \mathrm{E}$ near the equator are, on the whole, eastward after local sunset until sunrise, with a maximum of about $80^{-1}$ near midnight, and westward in the daytime with a maximum of about $80^{-1}$ near noon. Such a behavior is mainly due to a diurnal tide excited in the thermosphere. (4) Zonal wind patterns, in altitude-longitude coordinates, due to AGWs with periods of 1-4 h above $120 \mathrm{~km}$ altitude, exhibit wavy structures with horizontal and vertical scale lengths of about $300-1000 \mathrm{~km}$ and $30-100 \mathrm{~km}$, respectively. They move, as a whole, eastward at about $100^{-1}$ while changing the structures with time. Wind direction 


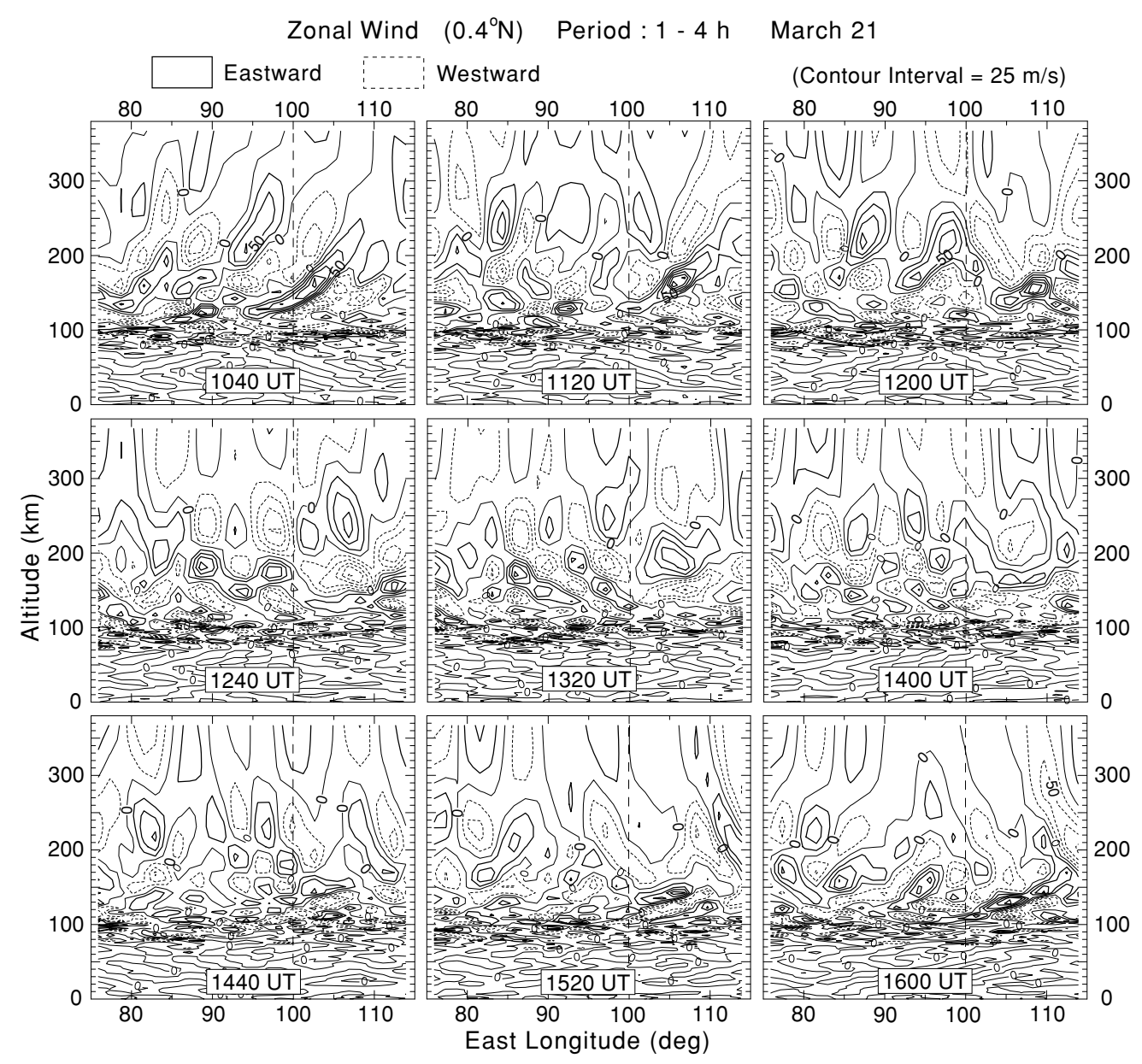

Fig. 11. Time variation of zonal wind with periods of $1-4 \mathrm{~h}$ at $0.4^{\circ} \mathrm{N}$ on March 21 in east longitude-altitude coordinates simulated by high-resolution KUGCM. Solid (dotted) line contours indicate eastward (westward) wind. The longitude of Kototabang is shown by dashed line.

changes within such scale lengths. The wavy structures change day by day.

The seasonal and yearly scintillation occurrence characteristics (item 1) are generally consistent with previous equatorial scintillation (bubble) observations (e.g., Basu and Basu, 1985; Basu et al., 1988; Burke et al., 2004; Gentile et al., 2006). The reason for the seasonal asymmetry is unknown. Eastward drifts of 350-m scale FAIs causing GPS scintillations also show the same seasonal asymmetry (Otsuka et al., 2006), i.e. the drifts between local sunset and 2200 LT are faster in March-April than in SeptemberOctober. Otsuka et al. (2006) speculate that this asymmetry is caused by seasonal asymmetry of neutral winds in the thermosphere. The seasonal occurrence pattern of equatorial scintillations (bubbles) is known to depend on longitude. In addition to the 350-m scale FAIs, bubbles are also accompanied by electron density irregularities with scale lengths of a few kilometers to tens of kilometers that cause GPS total electron content (TEC) fluctuations (Beach and Kintner, 1999). Analyzing statistically the GPS data of TEC fluctuations with such scale lengths obtained in India, Southeast Asia and Western Pacific, Ogawa et al. (2006) clarified that the scintillation occurrence patterns in 2003 (Fig. 1) were quite similar to the bubble occurrence patterns over the Philippines, Singapore and Indonesia, but that they deviate from those over Guam and India. More data acquisition for a full solar cycle is necessary to clarify the detailed seasonal pattern at Kototabang, which is located in the transition region between the Atlantic/Indian Ocean and Pacific Ocean sectors. The solar cycle dependence of the scintillation occurrences can be explained by the changes in transequatorial thermospheric wind, background electric field, vertical electron density gradient, electrical conductivities in the $E$ and $F$ region, among others that control the excitation of the RT instability (e.g., Maruyama and Matuura, 1984; Sultan, 1996).

As to item 2, Ogawa et al. (2006) also calculated cross correlation coefficients between $S_{4}$ and $T_{\text {bb }}$ at $0^{\circ} \mathrm{N}$ at five longitudes between $80^{\circ}-100^{\circ} \mathrm{E}$. They found that the coefficients during March 1-30 April 30, 2003, corresponding to Fig. 3 in this paper, decrease from $+0.29-+0.41$ at $80^{\circ}$ and $85^{\circ} \mathrm{E}$ to $+0.01-+0.17$ at $95^{\circ} \mathrm{E}$, which indicates that the scintillation occurrences over Kototabang may possibly be affected by the tropospheric convective activity at longitudes of $80^{\circ}-90^{\circ} \mathrm{E}$. Figure 3 confirms in part these results and moreover suggests that the tropospheric convective activity at northern and southern latitudes some distance from the equator also affects the scintillation occurrences.

As to item 3, using a FFT analysis, Ogawa et al. (2006) found that $S_{4}$ and $T_{\mathrm{bb}}$ have some common spectral peaks at periods between a few days and 13 days but that some 

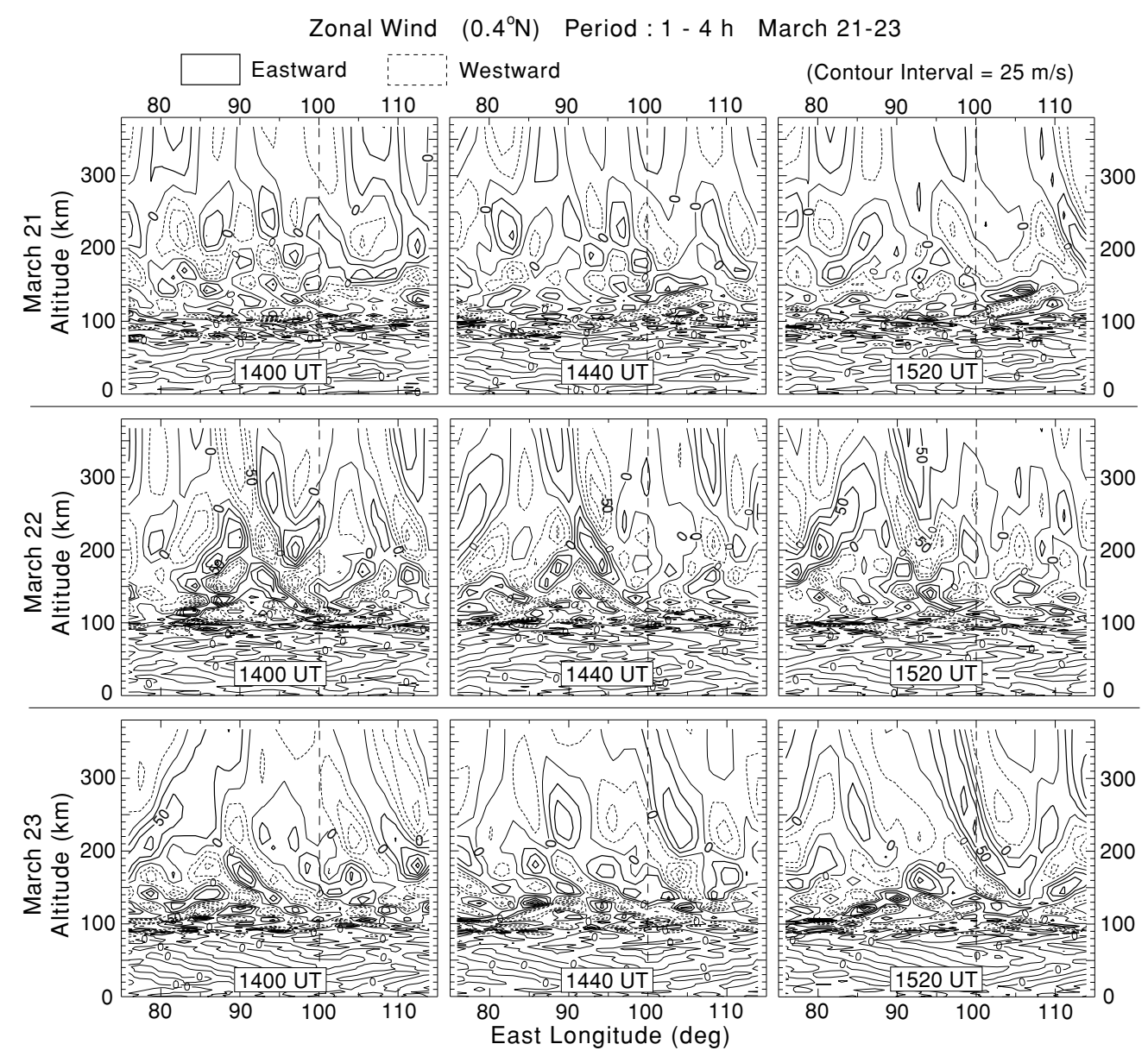

Fig. 12. Same as Fig. 11, but for March 21-23.

predominant periods appearing in $T_{\mathrm{bb}}$ do not always have counterparts in $S_{4}$, which are consistent with the results shown in Fig. 7. In this paper we have newly carried out wavelet analyses of $S_{4}, T_{\mathrm{bb}}$ and $\overline{u^{\prime 2}}$ data and found that some spectral peaks seen in $S_{4}$ and $T_{\mathrm{bb}}$ are also discernible in $\overline{u^{\prime 2}}$. Signatures of planetary and Kelvin waves in the equatorial mesosphere and ionosphere have been reported by, for example, Takahashi et al. $(2005,2006,2007)$ and Abdu et al. (2006a, b), who used ionosondes $\left(h^{\prime} F\right)$, meteor radars (neutral wind), airglow photometers (emission intensity), etc. Both planetary and Kelvin waves can modulate the $F$ region ionosphere to induce enhanced prereversal zonal electric field that initiates the onset of the RT instability to produce both spread- $F$ conditions (e.g., Abdu et al., 2006a) and scintillations (plasma bubbles), as shown in this paper.

It is very difficult to verify from our observational data that planetary-scale waves surely exist in the equatorial thermosphere and ionosphere. One way to resolve such a problem is numerical simulations. Our results (item 4) indicate that, in general, planetary and Kelvin waves with periods $\geq 2$ days cannot propagate upward beyond $125 \mathrm{~km}$ altitude (e.g. Forbes, 1996), which means that the $S_{4}$ fluctuations with periods longer than 2 days are not due to the direct response of the $F$ region plasma to the waves propagating up to altitudes of $250-300 \mathrm{~km}$. One scenario to explain these fluctuations may be that electric fields in the $E$ region modulated by the waves are transported to the $F$ region along the geomagnetic field lines to affect the RT instability. Farley et al. (1986) proposed a model to explain the prereversal enhancement of zonal electric field in the $F$ region, in which the eastward neutral wind near the solar terminator plays an important role. The eastward winds (item 4 and Fig. 10), mostly caused by a diurnal tide excited in the thermosphere after sunset, seem to be suitable for this model. A possibility of the modification of the prereversal electric field by $\mathrm{PW}$ oscillations in $E$ region zonal winds was discussed by Abdu et al. (2006a, b).

Many researchers have experimentally suggested an important role of AGWs in seeding bubbles and spread- $F$ (e.g., Kelley et al., 1981; Hysell et al., 1990; McClure et al., 1998; Lin et al., 2005). Kelley et al. (1981) found that spread- $F$ irregularities observed by a VHF radar show a clear association with a sinusoidal oscillation of the bottomside $F$ layer altitude. From satellite observations, Singh et al. (1997) showed that bubbles developed from wavy ion density structures with east-west wavelengths of 150 $800 \mathrm{~km}$ in the bottomside $F$ layer. Tsunoda (2005 and references therein) pointed out that the development of largescale $(\sim 400 \mathrm{~km})$ wavy structure in the bottomside $F$ layer is necessary and sufficient for equatorial spread- $F$ (bubble) occurrence and that variability in the wavy structure development might contribute to day-to-day variability of spread$F$. The wavy structures responsible for spread- $F$ occurrence were observed by, for example, Fukao et al. (2006) and 
Saito and Maruyama (2007). Ogawa et al. (2005) found that bubbles with longitudinal spacings of 200-250 km were embedded within wavy plasma structures with scales of a few hundreds to $1000 \mathrm{~km}$. Röttger $(1977,1981)$ suggested that medium-scale traveling ionospheric disturbances (MSTIDs), due to AGWs perhaps generated by convective activity in the intertropical convergence zone, had a reasonable influence on the large-scale structure of spread$F$ irregularities and, hence, on plasma bubbles (see also McClure et al., 1998). MSTID-like fluctuations that propagated southward were detected with an all-sky imager at Kototabang by Shiokawa et al. (2006). From model calculations, Vadas and Fritts (2004) suggested that AGWs with sufficiently large vertical wavelengths and group velocities excited by mesoscale convective complexes at equatorial latitudes can penetrate into the thermosphere, possibly contributing to the seeding of equatorial spread- $F$ (see also Vadas and Fritts, 2006; Vadas, 2007). Using the same KUGCM as we have used in this paper, Miyoshi and Fujiwara (2008) demonstrated that short-period (1.5-6 h) gravity waves with larger horizontal phase velocity (larger vertical wavelength) can penetrate into the thermosphere from the lower atmosphere and that day-to-day variability of horizontal wind fluctuations due to these gravity waves may induce ionospheric variability. Our simulations indicate that AGWs with periods of 1-4 h can propagate into the equatorial ionosphere, being able to produce directly eastward moving plasma structures with spatial scales of a few tens to $1000 \mathrm{~km}$, within which wind direction changes. Such plasma structures may be indirectly created through a process such that $E$ region electric fields perturbed by AGWs are transported to the $F$ region (e.g. Prakash, 1999). As shown in Fig. 12, the large-scale (a few hundreds to $1000 \mathrm{~km}$ ) horizontal wavy structures vary day by day, which may suggest that such a change in structure is responsible for the day-to-day variability of the GPS scintillation activity.

Apart from the AGW issue, Kudeki and Bhattacharyya (1999) found a vortex plasma flow pattern at about $250 \mathrm{~km}$ altitude that was related to post-sunset bottomside spread$F$ events. A collisional shear instability, which is driven by a plasma velocity shear, proposed by Hysell and Kudeki (2004) can produce large-scale (typically $\sim 200 \mathrm{~km}$ ) wave structures in the bottomside equatorial ionosphere (Hysell et al., 2004, 2006). We speculate that the vortical plasma flow and velocity shear may originate from the wavy structures shown in Figs. 11 and 12. To test this scenario, however, it is necessary to calculate the electric field and plasma drift caused by the neutral wind system that is simulated in this paper.

\section{Conclusions}

We have presented 4.5-year GPS ionospheric scintillation observations at Kototabang, Indonesia with the aim of investigating possible dynamical couplings between the ionosphere/thermosphere and troposphere over the equator. The scintillation activity is predominantly high between 2000 and 0100 LT in equinoctial months with a seasonal asymmetry, and decreases with decreasing solar activity from
2003 to 2007, which is in line with previous equatorial scintillation (bubble) observations at other longitudes. The $S_{4}$ activity over Kototabang appears to be related to tropospheric disturbances over the Indian Ocean to the west of Kototabang. The scintillation index $S_{4}$ shows clear dayto-day variability, with periods of about 2.5, 5, 8, 14 and 25 days. Similar periods are also found in Earth's brightness temperature $T_{\mathrm{bb}}$ and lower thermospheric neutral wind $\overline{u^{\prime 2}}$ variations, suggesting that $S_{4}$ and $\overline{u^{\prime 2}}$ are modulated by waves with periods similar to PWs from below.

The neutral wind system in the thermosphere simulated by using KUGCM indicates the following: (1) 2to 20-day waves, including planetary and Kelvin waves, dissipate rapidly above about $125 \mathrm{~km}$, and 0.5 - to $3-\mathrm{h}$ waves become predominant with increasing altitude beyond $100 \mathrm{~km}$, (2) zonal winds above $200 \mathrm{~km}$ altitude are, on the whole, eastward after local sunset $(\sim 1900$ LT) until sunrise ( $\sim 0600$ LT), (3) zonal wind patterns due to AGWs with periods of $1-4 \mathrm{~h}$ above $120 \mathrm{~km}$ altitude exhibit wavy structures with scale lengths of about $30-1000 \mathrm{~km}$ and, as a whole, move eastward at about $100^{-1}$ while changing the structures with time. The wind direction changes within such scale lengths. The wavy structures change day by day. These simulation results suggest that short-period gravity waves, which may contribute to the seeding of the RT instability generating plasma bubbles accompanied by scintillations, are generally present above $120 \mathrm{~km}$ altitude and that the background conditions necessary for the RT instability are modulated by planetary-scale atmospheric waves. We suppose that such a scenario can explain the day-to-day variability in the scintillation occurrences. Future work should investigate how ionospheric electric fields, electron density distribution, etc. are modulated with time, day and season by the simulated neutral winds.

Acknowledgments. GPS observations at the EAR site have been conducted in collaboration with RISH of Kyoto University and LAPAN of Indonesia since September 2002. We are deeply grateful to the staff of LAPAN for their extensive collaborations to the observations. We thank S. Sridharan and T. Yokoyama for their help in the data analysis. $T_{\mathrm{bb}}$ data were supplied through Kochi University, Japan. This work is supported by Grant-in-Aid for Scientific Research on Priority Area-764 (13136201) of the Ministry of Education, Culture, Sports, Science and Technology of Japan, and partly by the 21 st Century COE Program "Dynamics of the Sun-Earth-Life Interactive System (SELIS)" of Nagoya University.

\section{References}

Abdu, M. A., Outstanding problems in the equatorial ionospherethermosphere electrodynamics relevant to spread F, J. Atmos. Sol.-Terr. Phys., 63, 869-884, 2001.

Abdu, M. A., P. P. Batista, I. S. Batista, C. G. M. Brum, A. J. Carrasco, and B. W. Reinisch, Planetary wave oscillations in mesospheric winds, equatorial evening prereversal electric field and spread $F$, Geophys. Res. Lett., 33, L07107, doi:10.1029/2005GL024837, 2006a.

Abdu, M. A., T. K. Ramkumar, I. S. Batista, C. G. M. Brum, H. Takahashi, B. W. Reinisch, and J. H. Sobral, Planetary wave signatures in the equatorial atmosphere-ionosphere system, and mesosphere- $E$ - an $F$ region coupling, J. Atmos. Sol.-Terr. Phys., 68, 509-522, 2006 b.

Basu, Su. and S. Basu, Equatorial scintillations: Advances since ISEA-6, J. Atmos. Terr. Phys., 47, 753-768, 1985.

Basu, Su., S. Basu, J. P. MuClure, W. B. Hanson, and H. E. Whitney, High resolution topside in situ data of electron densities and $\mathrm{VHF} / \mathrm{GHz}$ scintillations in the equatorial region, J. Geophys. Res., 88, 403-415, 
1983

Basu, S., E. MacKenzie, and Su. Basu, Ionospheric constraints of VHF/UHF communications links during solar maximum and minimum periods, Radio Sci., 23, 363-378, 1988.

Beach, T. L. and P. M. Kintner, Simultaneous Global Positioning System observations of equatorial scintillations and total electron content fluctuations, J. Geophys. Res., 104, 22,553-22,565, 1999.

Burke, W. J., C. Y. Huang, L. C. Gentile, and L. Bauer, Seasonallongitudinal variability of equatorial plasma bubbles, Ann. Geophys., 22, 3089-3098, 2004.

Farley, D. T., E. Bonelli, B. G. Fejer, and M. F. Larsen, The prereversal of the zonal electric field in the equatorial ionosphere, J. Geophys. Res., 91, 13,723-13,728, 1986.

Forbes, J. M., Planetary waves in the thermosphere-ionosphere system, $J$. Geomag. Geoelectr., 48, 91-98, 1996.

Fukao, S., Y. Ozawa, T. Yokoyama, M. Yamamoto, and R. T. Tsunoda, First observations of the spatial structure of $F$ region 3-m-scale fieldaligned irregularities with Equatorial Atmosphere Radar in Indonesia, J. Geophys. Res., 109, A02304, doi:10.1029/2003JA010096, 2004.

Fukao, S., T. Yokoyama, T. Tayama, M. Yamamoto, T. Maruyama, and S. Saito, Eastward traverse of equatorial plasma plumes observed with the Equatorial Atmosphere Radar in Indonesia, Ann. Geophys., 24, 14111418, 2006

Gentile, L. C., W. J. Burke, and F. J. Rich, A global climatology for equatorial plasma bubbles in the topside ionosphere, Ann. Geophys., 24, 163-172, 2006.

Hocke, K. and T. Tsuda, Gravity waves and ionospheric irregularities over tropical convection zones observed by GPS/MET radio occultation, Geophys. Res. Lett., 28, 2815-2818, 2001.

Hysell, D. L. and E. Kudeki, Collisional shear instability in the equatorial $F$ region ionosphere, J. Geophys. Res., 109, A11301, doi:10. 1029/2004JA010636, 2004.

Hysell, D. L., M. C. Kelley, W. E. Swartz, and R. F. Woodman, Seeding and layering of equatorial spread $F$ by gravity waves, J. Geophys. Res., 95, 17,253-17,260, 1990.

Hysell, D. L., J. Chun, and J. L. Chau, Bottom-type scattering layers and equatorial spread F, Ann. Geophys., 22, 4061-4069, 2004.

Hysell, D. L., M. F. Larsen, C. M. Swenson, and T. F. Wheeler, Shear flow effects at the onset of equatorial spread $F, J$. Geophys. Res., 111, A11317, doi:10.1029/2006JA011963, 2006

Kelley, M. C., M. F. Larsen, C. LaHoz, and J. P. McClure, Gravity wave initiation of equatorial spread $F$ : A case study, J. Geophys. Res., 86, 9087-9100, 1981.

Kudeki, E. and S. Bhattacharyya, Postsunset vortex in equatorial $F$-region plasma drifts and implications for bottomside spread-F, J. Geophys. Res., 104, 28,163-28,170, 1999.

Laštovička, J., Forcing of the ionosphere by waves from below, J. Atmos. Sol.-Terr. Phys., 68, 479-497, 2006.

Lin, C. S., T. J. Immel, H. C. Yeh, S. B. Mende, and J. L. Burch, Simultaneous observations of equatorial plasma depletion by IMAGE and ROCSAT-1 satellites, J. Geophys. Res., 110, A06304, doi:10.1029/ 2004JA010774, 2005.

Maruyama, T. and N. Matuura, Longitudinal variability of annual changes in activity of equatorial spread $F$ and plasma bubbles, J. Geophys. Res., 89, 10,903-10,912, 1984.

McClure, J. P., S. Singh, D. K. Bamgboye, F. S. Johnson, and H. Kil, Occurrence of equatorial $F$ region irregularities: Evidence for tropospheric seeding, J. Geophys. Res., 103, 29,119-29,135, 1998.

Miyoshi, Y., Temporal variation of nonmigrating diurnal tide and its relation with the moist convective activity, Geophys. Res. Lett., 33, L11815, doi:10.1029/2006GL026702, 2006.

Miyoshi, Y. and H. Fujiwara, Excitation mechanism of intraseasonal oscillation in the equatorial mesosphere and lower thermosphere, J. Geophys. Res., 111, D14108, doi:10.1029/2005JD006993, 2006.

Miyoshi, Y. and H. Fujiwara, Gravity waves in the thermosphere simulated by a general circulation model, J. Geophys. Res., 113, D01101, doi: 10.1029/2007JD008874, 2008

Ogawa, T., E. Sagawa, Y. Otsuka, K. Shiokawa, T. J. Immel, S. B. Mende, and P. Wilkinson, Simultaneous ground- and satellite-based airglow observations of geomagnetic conjugate plasma bubbles in the equatorial anomaly, Earth Planets Space, 57, 385-392, 2005.

Ogawa, T., Y. Otsuka, K. Shiokawa, A. Saito, and M. Nishioka, Ionospheric disturbances over Indonesia and their possible association with atmospheric gravity waves from the troposphere, J. Meteor. Soc. Jpn., 84A, 327-342, 2006

Otsuka, Y., K. Shiokawa, T. Ogawa, and P. Wilkinson, Geomagnetic conjugate observations of equatorial airglow depletions, Geophys. Res. Lett.,
29(15), doi:10.1029/2002GL015347, 2002.

Otsuka, Y., K. Shiokawa, T. Ogawa, T. Yokoyama, M. Yamamoto, and S. Fukao, Spatial relationship of equatorial plasma bubbles and fieldaligned irregularities observed with an all-sky airglow imager and the Equatorial Atmosphere Radar, Geophys. Res. Lett., 31, L20802, doi:10.1029/2004GL020869, 2004.

Otsuka, Y., K. Shiokawa, and T. Ogawa, Equatorial ionospheric scintillations and zonal irregularity drifts observed with closely-spaced GPS receivers in Indonesia, J. Meteor. Soc. Jpn., 84A, 343-351, 2006.

Prakash, S., Production of electric field perturbations by gravity wave winds in the $E$ region suitable for initiating equatorial spread $F, J$. Geophys. Res., 104, 10,051-10,069, 1999.

Röttger, J., Travelling disturbances in the equatorial ionosphere and their association with penetrative cumulus convection, J. Atmos. Terr. Phys. 39, 987-998, 1977.

Röttger, J., Equatorial spread- $F$ by electric fields and atmospheric gravity waves generated by thunderstorms, J. Atmos. Terr. Phys., 43, 453-462, 1981

Saito, S. and T. Maruyama, Large-scale longitudinal variation in ionospheric height and equatorial spread $F$ occurrences observed by ionosondes, Geophys. Res. Lett., 34, L16109, doi:10.1029/ 2007GL030618, 2007.

Shiokawa, K., Y. Otsuka, T. Ogawa, and P. Wilkinson, Time evolution of high-altitude plasma bubbles imaged at geomagnetic conjugate points, Ann. Geophys., 22, 3137-3143, 2004.

Shiokawa, K., Y. Otsuka, and T. Ogawa, Quasiperiodic southward moving waves in 630-nm airglow images in the equatorial thermosphere, $J$. Geophys. Res., 111, A06301, doi:10.1029/2005JA011406, 2006.

Singh, S., F. S. Johnson, and R. A. Power, Gravity wave seeding of equatorial plasma bubbles, J. Geophys. Res., 102, 7399-7410, 1997.

Sridharan, S., T. Tsuda, R. A. Vincent, T. Nakamura, and Effendy, A report on radar observations of 5-8-day waves in the equatorial MLT region, J. Meteor. Soc. Jpn., 84A, 295-304, 2006.

Sultan, F. J., Linear theory and modeling of the Rayleigh-Taylor instability leading to the occurrence of equatorial spread $F, J$. Geophys. Res., 101, 26,875-26,891, 1996.

Takahashi, H., L. M. Lima, C. W. Wrasse, M. A. Abdu, I. S. Batista, D. Gobbi, R. A. Buriti, and P. P. Batista, Evidence on 2-4 day oscillations of the equatorial ionosphere $h^{\prime} F$ and mesospheric airglow emissions, Geophys. Res. Lett., 32, L12102, doi:10.1029/2004GL022318, 2005.

Takahashi, H., C. W. Wrasse, D. Pancheva, M. A. Abdu, I. S. Batista, L. M. Lima, P. P. Batista, B. R. Clemesha, and K. Shiokawa, Signatures of 3-6 day planetary waves in the equatorial mesosphere and ionosphere, Ann. Geophys., 24, 3343-3350, 2006.

Takahashi, H. et al., Signatures of ultra fast Kelvin waves in the equatorial middle atmosphere and ionosphere, Geophys. Res. Lett., 34, L11108, doi:10.1029/2007GL029612, 2007.

Tsuda, T. and K. Hocke, Application of GPS radio occultation data for studies of atmospheric waves in the middle atmosphere and ionosphere, J. Meteor. Soc. Jpn., 82, 419-426, 2004.

Tsuda, T., M. Nishida, C. Rocken, and R. H. Ware, A global morphology of gravity wave activity in the stratosphere revealed by the GPS occultation data (GPS/MET), J. Geophys. Res., 105, 7257-7273, 2000.

Tsunoda, R. T., On the enigma of day-to-day variability in the equatorial spread F, Geophys. Res. Lett., 32, L08103, doi:10.1029/ 2005 GL022512, 2005.

Vadas, S. L., Horizontal and vertical propagation and dissipation of gravity waves in the thermosphere from lower atmospheric and thermospheric sources, J. Geophys. Res., 112, A06305, doi:10.1029/2006JA011845, 2007

Vadas, S. L. and D. C. Fritts, Thermospheric responses to gravity waves arising from mesoscale convective complexes, J. Atmos. Sol.-Terr. Phys., 66, 781-804, 2004

Vadas, S. L. and D. C. Fritts, Influence of solar variability on gravity wave structure and dissipation in the thermosphere from tropospheric convection, J. Geophys. Res., 111, A10S12, doi:10.1029/2005JA011510, 2006.

Woodman, R. F. and C. LaHoz, Radar observations of $F$ region equatorial irregularities, J. Geophys. Res., 81, 5447-5466, 1976.

Yokoyama, T., S. Fukao, and M. Yamamoto, Relationship of the onset of equatorial $F$ region irregularities with the sunset terminator observed with the Equatorial Atmosphere Radar, Geophys. Res. Lett., 31, L24804, doi:10.1029/2004GL021529, 2004.

T. Ogawa (e-mail: taogawa@nict.go.jp), Y. Miyoshi, Y. Otsuka, T. Nakamura, and K. Shiokawa 